\title{
Chemical Polymerization Kinetics of Poly-O-Phenylenediamine and Characterization of the Obtained Polymer in Aqueous Hydrochloric Acid Solution Using $\mathrm{K}_{2} \mathrm{Cr}_{2} \mathrm{O}_{7}$ as Oxidizing Agent
}

\author{
S. M. Sayyah, ${ }^{1}$ A. B. Khaliel, ${ }^{1}$ Ahmed A. Aboud, ${ }^{2}$ and S. M. Mohamed $^{1}$ \\ ${ }^{1}$ Polymer Research Laboratory, Chemistry Department, Faculty of Science, Beni-Suef University, Beni-Suef 62514, Egypt \\ ${ }^{2}$ Physics Department, Faculty of Science, Beni-Suef University, Beni-Suef 62514, Egypt \\ Correspondence should be addressed to S. M. Sayyah; smsayyah@hotmail.com
}

Received 18 January 2014; Revised 25 March 2014; Accepted 29 April 2014; Published 12 June 2014

Academic Editor: Yulin Deng

Copyright $\odot 2014$ S. M. Sayyah et al. This is an open access article distributed under the Creative Commons Attribution License, which permits unrestricted use, distribution, and reproduction in any medium, provided the original work is properly cited.

\begin{abstract}
The oxidative chemical polymerization of o-phenylenediamine (OPDA) was studied in hydrochloric acid solution using potassium dichromate as oxidant at $5^{\circ} \mathrm{C}$. The effects of potassium dichromate, hydrochloric acid, and monomer concentrations on the polymerization reaction were investigated. The order of reaction with respect to potassium dichromate, hydrochloric acid, and monomer concentration was found to be 1.011, 0.954, and 1.045, respectively. Also, the effect of temperature on the polymerization rate was studied and the apparent activation energy of the polymerization reaction was found to be $63.658 \mathrm{~kJ} / \mathrm{mol}$. The obtained polymer was characterized using XPS, IR, UV-visible, and elemental analysis. The surface morphology of the obtained polymers was characterized by X-ray diffraction and transmission electron microscopy (TEM). The TGA analysis was used to confirm the proposed structure and number of water molecules in each polymeric chain unit. The ac conductivity $\left(\sigma_{\mathrm{ac}}\right)$ of $(\mathrm{POPDA})$ was investigated as a function of frequency and temperature. The ac conductivity was interpreted as a power law of frequency. The frequency exponent (s) was found to be less than unity and decreased with the increase of temperature, which confirms that the correlated barrier hopping model was the dominant charge transport mechanism.
\end{abstract}

\section{Introduction}

Polyaniline as an electrically conductive polymer has attracted considerable attention, because of its excellent environmental stability in the electroconducting form and electrical and optical properties [1,2]. It has various potential applications in many high performance devices [3-9]. A common feature of conducting polymer is conjugation of $\pi$-electrons extending over the length of the polymer backbone [10]. Polymerization of conducting polymer may be performed by chemical [11] or electrochemical [12] methods. Various chemical oxidizing agents, such as potassium dichromate [13], potassium iodate [14], hydrogen peroxide [15], ferric chloride, or ammonium persulphate, were used [16]. The applications of polyaniline are limited due to its poor processability [17], which is true for most conducting polymers. Several studies have been done in order to improve the solubility of polyaniline; among them is using functionalized protonic acids as dopant, like p-toluenesulphonic acid, octyl-benzene-sulphonic acid, dodecyl benzene-sulphonic acid [18], poly(styrene) sulphonic acid [19], and phosphoric acid esters [20]. An alternative method to obtain soluble conductive polymers is the polymerization of aniline derivatives. The studied aniline derivatives are alkyloxy, hydroxy, and chloroaniline and substitution at the nitrogen atom was reported by Sayyah et al. [21-24] to improve the solubility of polyaniline. The substituted group of aniline affects not only the polymerization reaction but also the properties of the polymer obtained. The kinetics of chemical polymerization of 3-methylaniline, 3-chloroaniline, 3-hydroxyaniline, 3-methoxyaniline, and $\mathrm{N}$-methyl aniline in hydrochloric acid solution using sodium dichromate as oxidant and characterization of the polymer obtained by IR, UV-visible and elemental analysis, X-ray diffraction, 
scanning electron microscopy, TGA-DTA analysis, and ac conductivity have been investigated by Sayyah et al. [25-28].

The present work intends to study the kinetics of the oxidative chemical polymerization of o-phenylenediamine in aqueous $\mathrm{HCl}$ medium and potassium dichromate as oxidant. The obtained polymer is characterized by XPS, IR, UVvisible, TGA, elemental analysis, $\mathrm{X}$-ray, transmission electron microscopy (TEM), and ac conductivity measurements.

\section{Experimental}

2.1. Materials. O-phenylenediamine was provided by Aldrich chemical Co. (Germany). Concentrated hydrochloric acid, pure grade product, was provided by El-Nasr pharmaceutical chemical Co., Egypt. Potassium dichromate was provided by Sigma-Aldrich chemical Co. (Germany). Doubly distilled water was used to prepare all the solutions needed in the kinetic studies.

2.2. Oxidative Aqueous Polymerization of O-Phenylenediamine Monomer. The polymerization reaction was carried out in a well-stoppered conical flask of $250 \mathrm{~mL}$ capacity; addition of OPDA amount in $25 \mathrm{~mL} \mathrm{HCl}$ of known molarity was followed by the addition of the required amount of potassium dichromate as oxidant in water $(25 \mathrm{~mL})$ to the reaction mixture. The orders of addition of substances were kept constant in all the performed experiments. The stoppered conical flasks were then placed in an automatically controlled thermostat at the required temperature. The flasks were shaken (15 shakings/10 s/15 min) by using an automatic shaker. The flasks were filtrated using a Buchner funnel; then the obtained polymer was washed with distilled water and finally dried till constant weight in vacuum oven at $60^{\circ} \mathrm{C}$.

2.3. Elemental Analysis, Infrared, and Ultraviolet Spectroscopy. The carbon, hydrogen, and nitrogen contents of the prepared polymer were carried out in the microanalytical laboratory at Cairo University by using oxygen flask combustion and a dosimat E415 titrator (Switzerland).

The infrared spectroscopic analysis of the prepared polymer was carried out in the microanalytical laboratory at Cairo University by using a Shimadzu FTIR-430 Jasco spectrophotometer and $\mathrm{KBr}$ disc technique.

The ultraviolet-visible absorption spectra of the monomer and the prepared polymer sample were measured using Shimadzu UV spectrophotometer (M 160 PC) at room temperature in the range $200-400 \mathrm{~nm}$ using dimethylformamide as a solvent and reference.

2.4. X-Ray Photoelectron Spectroscopy (XPS). An XPS spectrum was obtained on XPS-thermo scientific spectrometer, Model: K-ALDH in Central metallurgical research and development institute (CMRDI). Polymer was mounted on a standard sample holder using double-sided adhesive tape. Survey and XPS spectra were obtained with $\mathrm{Al} \mathrm{K} \alpha$ monochromatic $\mathrm{X}$-ray with the resolution of $0.7 \mathrm{eV}$.
2.5. Thermal Gravimetric Analysis (TGA), Transmission Electron Microscopy (TEM), and X-Ray Analysis. Thermal gravimetric analysis (TGA) of the polymer sample was performed using a SHIMADZU DT-30 thermal analyzer. The weight loss was measured from ambient temperature up to $600^{\circ} \mathrm{C}$ at rate of $20^{\circ} \mathrm{C} / \mathrm{min}$ to determine the rate of degradation of the polymer.

The X-ray diffractometer type Philips 1976 Model 1390 was used to investigate the phase structure of the polymer powder under the following condition which kept constant during the analysis processes: $\mathrm{Cu}$ : $\mathrm{X}$-ray tube, scan speed $=$ $8 / \mathrm{min}$, current $=30 \mathrm{~mA}$, voltage $=40 \mathrm{kv}$, and preset time $=$ $10 \mathrm{~s}$.

The inner cavity and wall thickness of the prepared polymer were investigated using transmission electron microscopy (TEM) JEOL JEM-1200 EX П (Japan).

2.6. Conductivity Measurements. The ac conductivity was measured using Philips RCL bridge (digital and computerized) at a frequency range $0.1-100 \mathrm{kHz}$ and over temperature range $30-80^{\circ} \mathrm{C}$. The temperature was controlled by the use of a double wound electric oven.

The ac conductivity $\sigma_{\mathrm{ac}}$ value was calculated using the relation

$$
\sigma_{\mathrm{ac}}=\varepsilon^{\prime \prime} \omega \varepsilon_{o}
$$

where $\omega=2 \pi f$ and $f$ is the applied frequency.

\section{Results and Discussion}

3.1. Determination of the Optimum Polymerization Conditions. To optimize the condition for polymerization of ophenylenediamine, the concentrations of potassium dichromate, hydrochloric acid, and monomer were investigated with keeping the total volume of the reaction mixture constant at $50 \mathrm{~mL}$.

3.1.1. Effect of Potassium Dichromate Concentration. Both of the monomer and $\mathrm{HCl}$ concentrations are fixed at $0.1 \mathrm{M}$ while the oxidant concentrations were varied from 0.04 to $0.5 \mathrm{M}$ at $5 \pm 0.2^{\circ} \mathrm{C}$ to investigate the optimum polymerization condition of $\mathrm{K}_{2} \mathrm{Cr}_{2} \mathrm{O}_{7}$. The yield-time curve was represented in Figure 1, from which it is clear that the obtained yield increased with the increase of $\mathrm{K}_{2} \mathrm{Cr}_{2} \mathrm{O}_{7}$ reaching maximum value at $0.3 \mathrm{M}$. From the left part of the curve it is clear that the polymer yield increases from $0.04 \mathrm{M}$ to $0.3 \mathrm{M}$ then decreases from $0.3 \mathrm{M}$ to $0.5 \mathrm{M}$. This could be due to the fact that, in the first part of the curve, the produced initiator ion radical moieties activate the backbone and simultaneously produced the o-phenylenediamine ion radical, which takes place immediately, and, therefore, yield increases with the increase of potassium dichromate concentration up to $0.3 \mathrm{M}$. But in the second part of the curve, the polymer yield decreases with increasing $\mathrm{K}_{2} \mathrm{Cr}_{2} \mathrm{O}_{7}$ concentration, may be due to a high concentration of oxidant promote the formation of low molecular weight oxidation product and also degrade the product polymer which easily soluble in water [13]. 


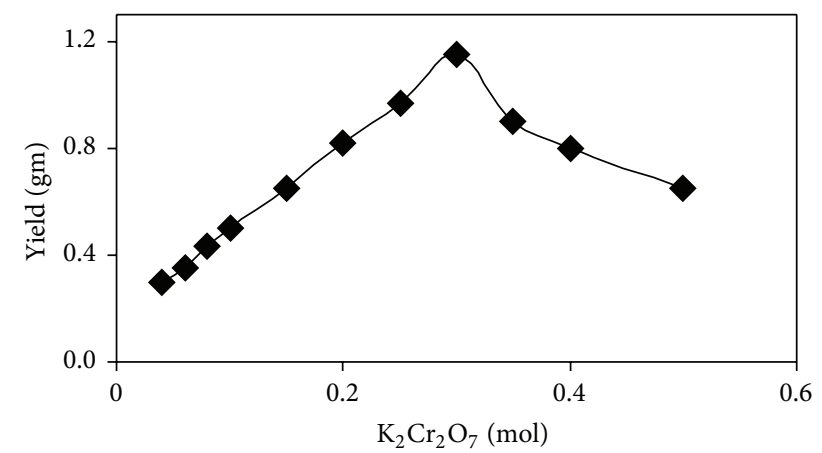

Figure 1: Yield- $\mathrm{K}_{2} \mathrm{Cr}_{2} \mathrm{O}_{7}$ concentration effect on the aqueous oxidative polymerization of poly-o-phenylenediamine (POPDA).

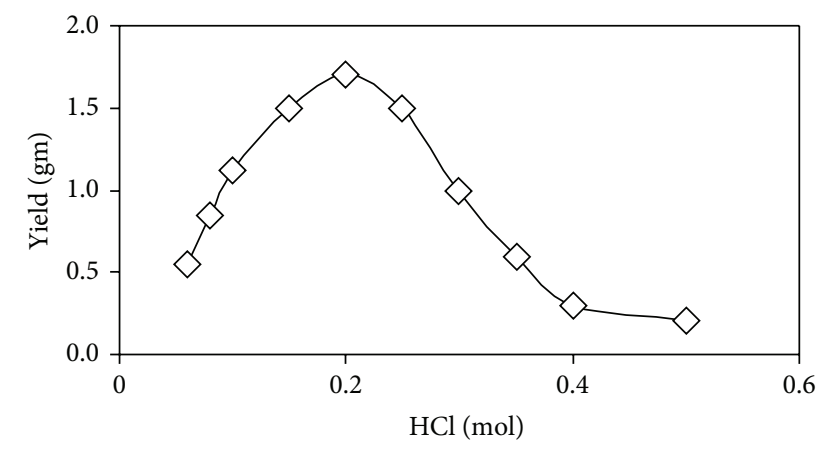

FIGURE 2: Yield-HCl concentration effect on the aqueous oxidative polymerization of poly-o-phenylenediamine (POPDA).

3.1.2. Effect of $\mathrm{HCl}$ Concentration. The effect of $\mathrm{HCl}$ concentration on the aqueous oxidative polymerization of OPDA was investigated using constant concentration of $\mathrm{K}_{2} \mathrm{Cr}_{2} \mathrm{O}_{7}$ at $0.3 \mathrm{M}$ and monomer concentration at $0.1 \mathrm{M}$ and using different concentration of $\mathrm{HCl}$ at $5 \pm 0.2^{\circ} \mathrm{C}$. The yield-time data was represented in Figure 2, from which it is clear that the obtained yield increases in the acid concentration range from 0.04 to 0.2 then decreases gradually up to $0.5 \mathrm{M}$. This behavior may be due to, at higher concentration of $\mathrm{HCl}$, the degradation of the polymer in the early stages of the reaction, which may be due to the hydrolysis of polyemeraldine chain [13].

3.1.3. Effect of O-Phenylenediamine Concentration. The effect of monomer concentration on the polymerization efficiency was investigated in the range of monomer concentration from 0.02 to $0.5 \mathrm{M}$ and the data was represented in Figure 3, from which it is clear that the optimum yield formation is obtained at $0.1 \mathrm{M}$ of the monomer concentration.

\subsection{The Kinetic Study of the Polymerization Reaction}

3.2.1. Effect of Potassium Dichromate Concentration. The aqueous polymerization of OPDA $(0.1 \mathrm{~mol})$ was carried out in $25 \mathrm{~mL}$ of $\mathrm{HCl}$ solution $(0.2 \mathrm{~mol})$ in the presence of $25 \mathrm{~mL}$ potassium dichromate as oxidant of different molarities at $5^{\circ} \mathrm{C}$ for different time intervals. The yield-time curves were

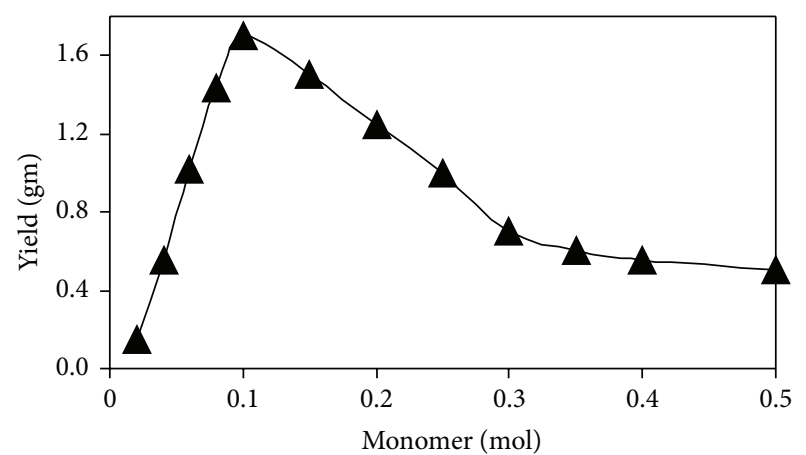

FIGURE 3: Yield-monomer concentration effect on the aqueous oxidative polymerization of poly-o-phenylenediamine (POPDA).

plotted for different oxidant concentrations and the data are graphically represented in Figure 4(a). The initial and overall reaction rates were determined using the following equation:

$$
\text { Rate }\left(R_{i}\right)=\frac{P}{V \times M \times t},
$$

where $P$ is the weight of the obtained polymer, $t$ is the time in seconds, $M$ is the molecular weight of the monomer, and $V$ is the reaction volume in liter.

The initial and overall reaction rates of the polymerization reaction increase with the increase of oxidant concentration in the range between 0.05 and $0.3 \mathrm{~mol} / \mathrm{L}$. The oxidant exponent was determined from the relation between logarithm of the initial rate of polymerization Log $\left(R_{i}\right)$ and logarithm of the oxidant concentration. A straight line was obtained which has a slope of 1.011 as represented in Figure 4(b). This means that the polymerization reaction of OPDA is a firstorder reaction with respect to the oxidant.

3.2.2. Effect of Hydrochloric Acid Concentration. The polymerization of OPDA $(0.1 \mathrm{~mol})$ in $25 \mathrm{~mL}$ of $\mathrm{HCl}$ with different molarities was carried out by addition of $25 \mathrm{~mL}$ potassium dichromate $(0.3 \mathrm{~mol} / \mathrm{L})$ as oxidant at $5^{\circ} \mathrm{C}$ for different time intervals. The concentration of the monomer and oxidant were kept constant during the study of $\mathrm{HCl}$ effect on the polymerization reaction. The experiments were carried out as described in Section 2.2, and the yield-time curve was plotted for each acid concentration used. The data are graphically represented in Figure 5(a), from which it is clear that both the initial and overall reaction rates of the polymerization reaction increase with the increasing of $\mathrm{HCl}$ concentrations in the range between 0.05 and $0.2 \mathrm{~mol} / \mathrm{L}$. The $\mathrm{HCl}$ exponent determined from the slope of the straight line represented in Figure 5(b) was found to be 0.954, which means that the polymerization order with respect to the $\mathrm{HCl}$ concentration is a first-order reaction.

3.2.3. Effect of Monomer (OPDA) Concentration. The aqueous polymerization of OPDA was carried out in $25 \mathrm{~mL}$ of $\mathrm{HCl}$ solution $(0.2 \mathrm{~mol} / \mathrm{L})$ in the presence of $25 \mathrm{~mL}$ potassium dichromate $(0.3 \mathrm{~mol} / \mathrm{L})$ as oxidant at $5^{\circ} \mathrm{C}$ for different time intervals. The yield-time curve was plotted for each monomer 


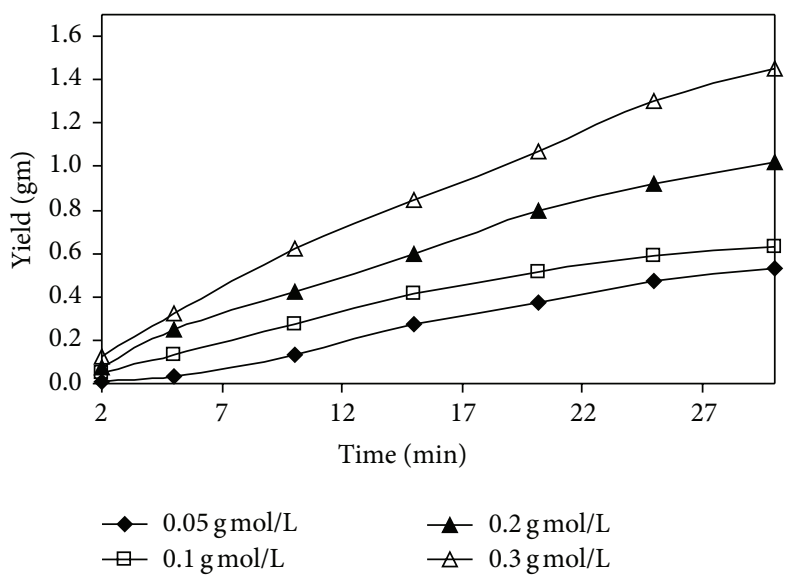

(a)

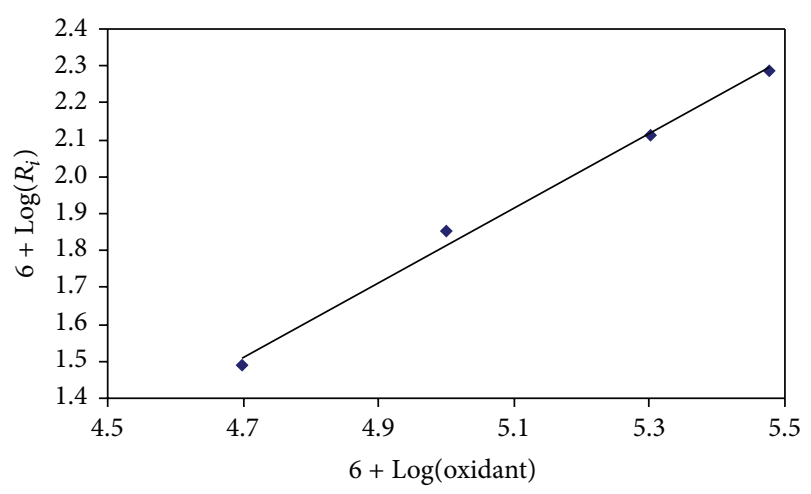

(b)

FIGURE 4: (a) Yield-time curve for the effect of potassium dichromate concentration on the polymerization (POPDA) at different time intervals. (b) Double logarithmic plot of the initial rate and oxidant concentration of POPDA.

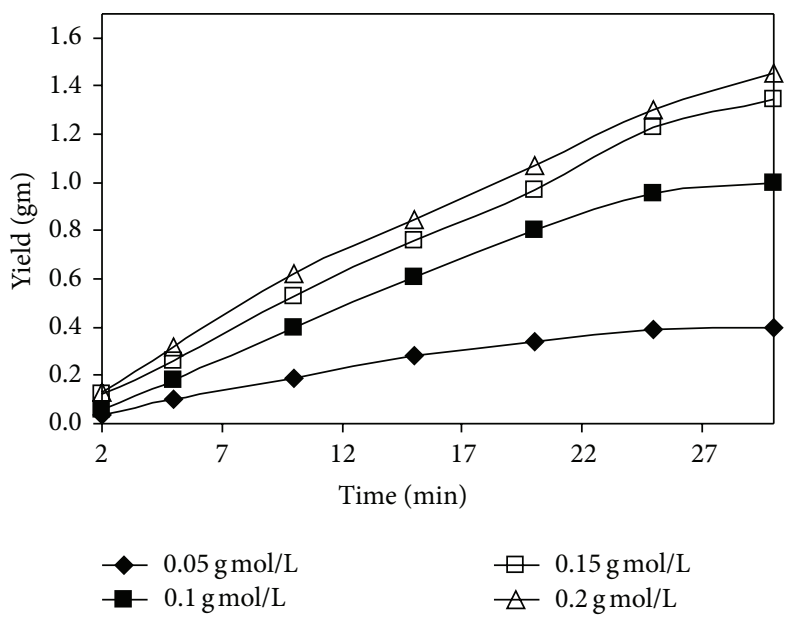

(a)

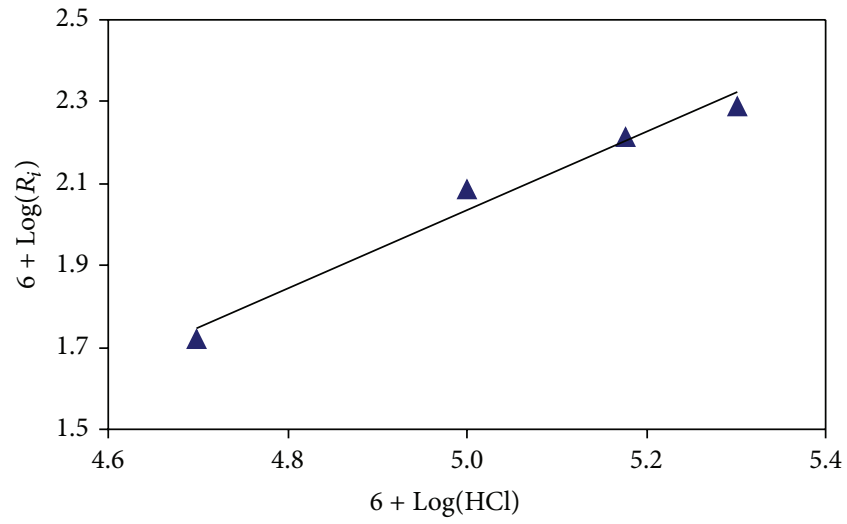

(b)

FIGURE 5: (a) Yield-time curve for the effect of $\mathrm{HCl}$ concentration on the aqueous oxidative polymerization of (POPDA) at different time intervals. (b) Double logarithmic plot of the initial rate and $\mathrm{HCl}$ concentration of POPDA.

concentration used. The data are graphically represented in Figure 6(a). The monomer exponent was determined from the slope of the straight line represented in Figure 6(b) for the relation between $\log R_{i}$ and logarithm of the monomer concentration. The slope of this linear relationship was found to be 1.045 . This means that the polymerization reaction with respect to the monomer concentration is a first-order reaction.

\subsection{Calculation of the Thermodynamic Activation Parame-} ters. The polymerization of OPDA $(0.1 \mathrm{~mol} / \mathrm{L})$ in $25 \mathrm{~mL}$ of $0.2 \mathrm{~mol} / \mathrm{L} \mathrm{HCl}$ in presence of $25 \mathrm{~mL}$ potassium dichromate $(0.3 \mathrm{~mol} / \mathrm{L})$ as oxidant solution was carried out at 5,10 , and $15^{\circ} \mathrm{C}$ for different time periods. The yield-time curves were graphically represented in Figure 7 , from which it is clear that both of the initial and overall reaction rates increase with raising the reaction temperature. The apparent activation energy $\left(E_{\mathrm{a}}\right)$ of the aqueous polymerization reaction of o-phenylenediamine was calculated using the following Arrhenius equation:

$$
\log (K)=\frac{-E_{a}}{2.303 R T}+C
$$

where $K$ is the rate, $R$ is the universal gas constant, $T$ is the reaction temperature, and $C$ is constant.

By plotting $\log R_{i}$ against $1 / T$, which gave a straight line as shown in Figure 8, and from the slope we can calculate the activation energy. The apparent activation energy for this system is $63.658 \mathrm{~kJ} / \mathrm{mol}$. The Enthalpy and entropy of 


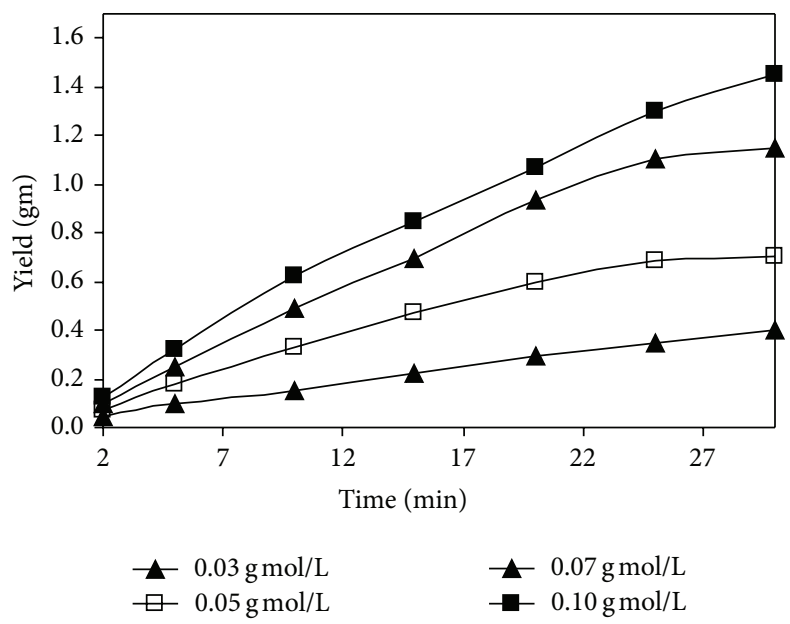

(a)

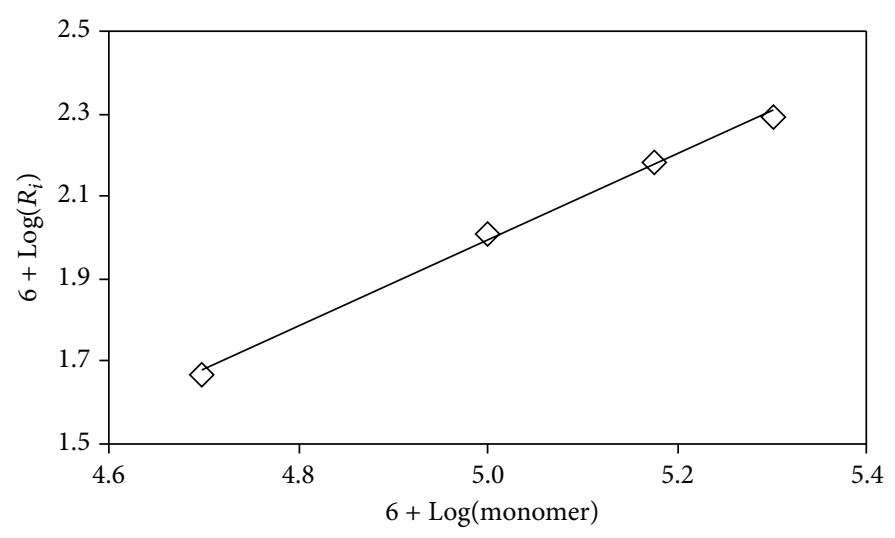

(b)

FIGURE 6: (a) Conversion-monomer/mol concentration effect on the aqueous oxidative polymerization of (POPDA) at different time intervals. (b) Double logarithmic plot of the initial rate and monomer concentration of POPDA.

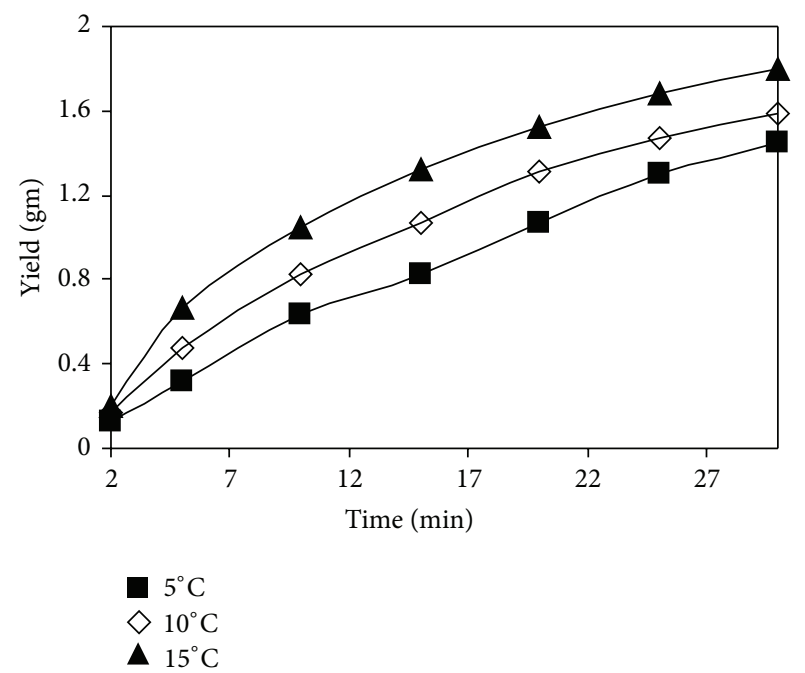

Figure 7: Yield-time curve for the effect of temperature on the aqueous oxidative polymerization of POPDA.

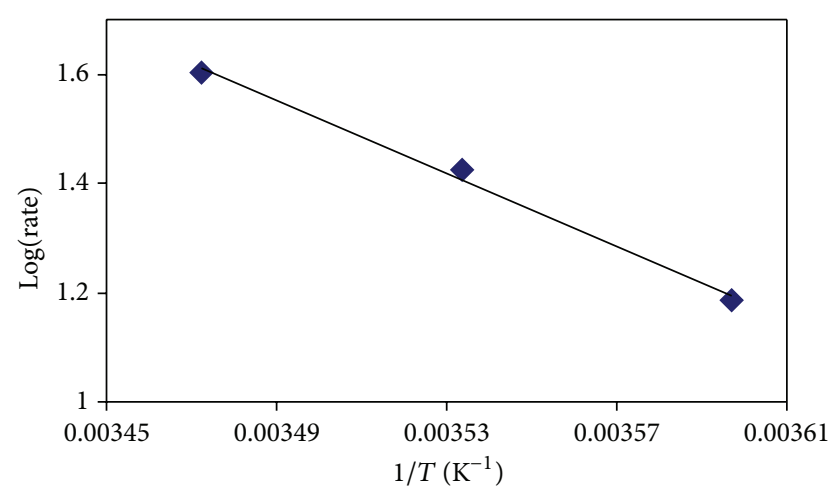

FIGURE 8: The relation between the logarithm of initial rate and (1/T) for aqueous oxidative polymerization of POPDA.

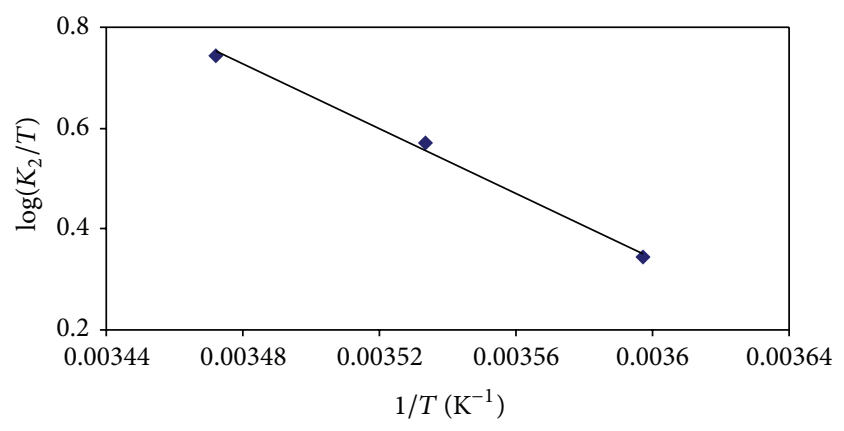

Figure 9: The relation between $\log K_{2} / T$ and $1 / T$ for poly-ophenylenediamine (POPDA).

activation for the polymerization reaction can be calculated by the calculation of $K_{2}$ from the following equation:

Reaction Rate $=K_{2}[\text { oxidant }]^{1.011}[\mathrm{HCl}]^{0.954}[\text { monomer }]^{1.045}$.

The values of $K_{2}$ at 5,10 , and $15^{\circ} \mathrm{C}$ were $6.131 \times 10^{-6}$, $1.054 \times 10^{-5}$, and $1.594 \times 10^{-5}$, respectively. The enthalpy $\left(\Delta H^{*}\right)$ and entropy $\left(\Delta S^{*}\right)$ of activation associated with $K_{2}$ were calculated using Eyring equation

$$
K_{2}=\left(\frac{R T}{N h}\right) e^{\Delta S^{*} / R} \cdot e^{-\Delta H^{*} / R T}
$$

where $K_{2}$ is the rate constant, $N$ is the Avogadro's number, $R$ is the universal gas constant, and $h$ is planks constant.

By dividing the above equation by $T$ and taking its natural logarithm we obtain the following equation:

$$
\operatorname{Ln}\left(\frac{K_{2}}{T}\right)=\ln \left(\frac{R}{N h}\right)+\frac{\Delta S^{*}}{R}+\frac{-\Delta H^{*}}{R T} .
$$


Figure 9 shows the relation between $K_{2} / T$ versus $1 / T$, which gives a linear relationship with $\left(-\Delta H^{*}\right) / R$ and intercept line $\left(\ln R / N h+\Delta S^{*} / R\right)$ from the slops and intercept; the values of $\Delta H^{*}$ and $\Delta S^{*}$ were found to be $61.48 \mathrm{kJmol}^{-1}$ and $29.95 \mathrm{Jmol}^{-1} \mathrm{~K}^{-1}$, respectively.

The intramolecular electron transfer steps for the oxidation reaction are endothermic as indicated by the value of $\Delta H^{*}$. The contributions of $\Delta H^{*}$ and $\Delta S^{*}$ to the rate constant seem to compensate each other. This fact suggests that the factors controlling $\Delta H^{*}$ must be closely related to those controlling $\Delta S^{*}$. Therefore, the salvation state of the encounter compound could be important in determination of $\Delta H^{*}$. Consequently, the relatively small enthalpy of activation can be explained in terms of the formation of more solvated complex.

3.4. Polymerization Mechanism. The aqueous oxidative polymerization of o-phenylenediamine is described in the Experimental section and follows three steps [29].

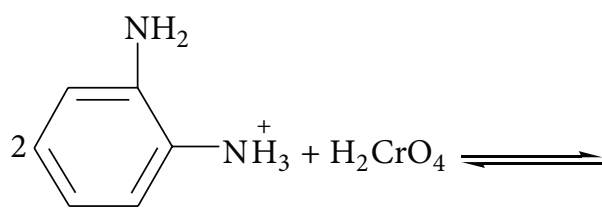

The Initial Step. Potassium dichromate in acidified aqueous solution produces chromic acid as shown in

$$
\mathrm{K}_{2} \mathrm{Cr}_{2} \mathrm{O}_{7}+\mathrm{H}_{2} \mathrm{O}+2 \mathrm{H}^{+}=2 \mathrm{~K}^{+}+2 \mathrm{H}_{2} \mathrm{CO}_{4} .
$$

This reaction is controlled by the change in $\mathrm{pH}$; the orange red dichromate ions $\left(\mathrm{Cr}_{2} \mathrm{O}_{7}\right)^{2-}$ are in equilibrium with the $\left(\mathrm{HCrO}_{4}\right)^{-}$in the range of $\mathrm{pH}$-values between 2 and 6 , but at $\mathrm{pH}$ below 1 the main species is $\left(\mathrm{H}_{2} \mathrm{CrO}_{4}\right)$ and the equilibria can occur as follows:

$$
\begin{gathered}
\left(\mathrm{HCrO}_{4}\right)^{-} \rightleftharpoons\left(\mathrm{CrO}_{4}\right)^{2-}+\mathrm{H}^{+} \quad \mathrm{K}=10^{-5.9} \\
\left(\mathrm{H}_{2} \mathrm{CrO}_{4}\right) \rightleftharpoons\left(\mathrm{HCrO}_{4}\right)^{-}+\mathrm{H}^{+} \quad \mathrm{K}=4.1 \\
2\left(\mathrm{HCrO}_{4}\right)^{-} \rightleftharpoons\left(\mathrm{Cr}_{2} \mathrm{O}_{7}\right)^{2-}+\mathrm{H}_{2} \mathrm{O} \quad \mathrm{K}=10^{-2.2} .
\end{gathered}
$$

The chromic acid withdraws one electron from each protonated OPDA and probably forms a metastable complex as shown in (11):

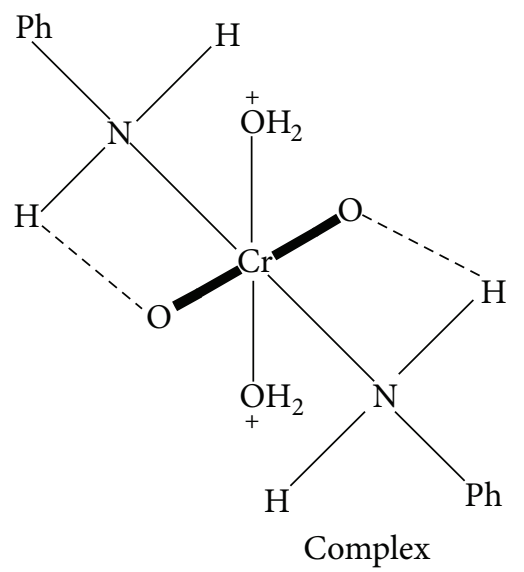

The complex undergoes dissociation to form monomer cation radical as shown in (12):

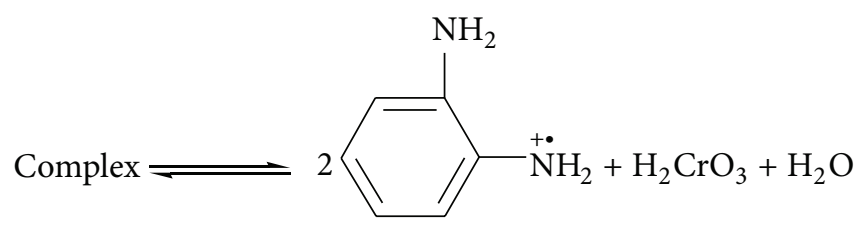

Generally, the initial step is rapid and may occur in short time, 0-5 min (autocatalytic reaction); no polymeric product is being obtained. After $5 \mathrm{~min}$ of the polymerization reaction, the polymeric products are obtained.
Propagation Step. This step involves the interaction between the formed radical cation and the monomer to form a dimer radical cation. In the case of $\mathrm{Cr}(\mathrm{VI})$ oxidation of the organic compounds, $\mathrm{Cr}(\mathrm{VI})$ is reduced to $\mathrm{Cr}(\mathrm{IV})$ first and then to 
TABLE 1: Solubility of poly-o-phenylenediamine (POPDA) in different solvents at $20^{\circ} \mathrm{C}$.

\begin{tabular}{lc}
\hline Solvent & Solubility of (POPDA) in $(\mathrm{g} / \mathrm{L})$ \\
\hline N-methyl-2-pyrrolidone & Completely soluble \\
Dimethylformamide & 2.235 \\
Acetone & 1.679 \\
Methanol & 1.074 \\
Iso propanol & 0.879 \\
\hline
\end{tabular}

Cr(III) [29]. Transfer of two electrons from two monomer ions radical by $\mathrm{H}_{2} \mathrm{CrO}_{4}$ produces para semidine salt along with chromous acid $\mathrm{H}_{2} \mathrm{Cr}_{2} \mathrm{O}_{3}(\mathrm{Cr}(\mathrm{IV}))$. The intermediately produced $\mathrm{Cr}(\mathrm{IV})$ oxidises para semidine to pernigraniline salt (PS) at suitable low $\mathrm{pH}$ and the PS acts as a catalyst for conversion of OPDA to POPDA:

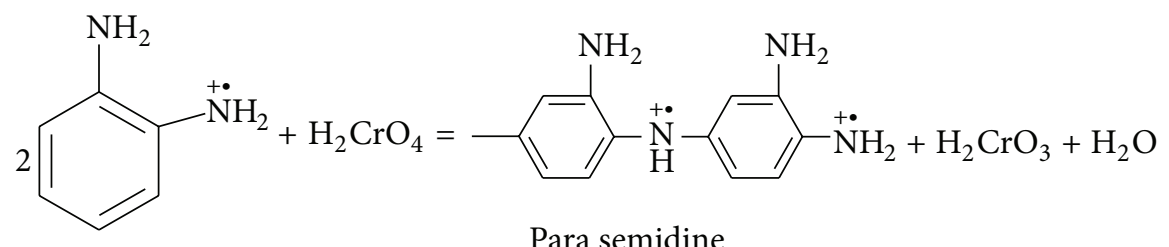

Para semidine

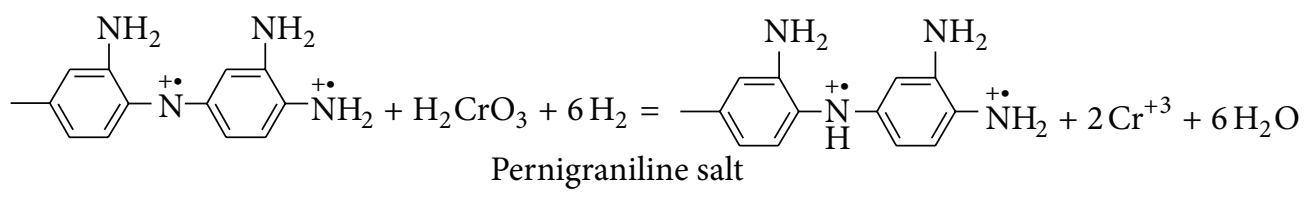

This reaction is followed by further reaction of the formed dimmer radical cations with monomer molecules to form trimer radical cations and so on. The degree of polymerization depends on different factors such as dichromate concentration, $\mathrm{HCl}$ concentration, monomer concentration, and temperature. By adding (7), (11), (12), (13), and (14),

$$
12 \mathrm{OPDA}+5 \mathrm{~K}_{2} \mathrm{Cr}_{2} \mathrm{O}_{7}+34 \mathrm{H}^{+}=6 \mathrm{PS}+10 \mathrm{Cr}^{3+}+10 \mathrm{~K}^{+}+35 \mathrm{H}_{2} \mathrm{O} \text {. }
$$

Termination Step. Termination of the reaction occurs by the addition of ammonium hydroxide solution in an equimolar amount to $\mathrm{HCl}$ present in the reaction medium (till $\mathrm{pH}=7$ ), which leads to cessation of the redox reaction. The reaction could occur as follows:<smiles>Nc1ccc(NNc2ccc(Nc3ccccc3N)cc2N)cc1N</smiles> 
TABLE 2: The XPS elemental analysis of poly-o-phenylenediamine (POPDA).

\begin{tabular}{|c|c|c|c|c|c|c|c|c|c|}
\hline \multicolumn{2}{|c|}{$\mathrm{C} \%$} & \multicolumn{2}{|c|}{ N\% } & \multicolumn{2}{|c|}{$\mathrm{Cl} \%$} & \multicolumn{2}{|c|}{ O\% } & \multicolumn{2}{|c|}{$\mathrm{Cr} \%$} \\
\hline Calc. & Found & Calc. & Found & Calc. & Found & Calc. & Found & Calc. & Found \\
\hline 57.21 & 56.11 & 22.25 & 21.89 & 7.05 & 6.94 & 3.18 & 3.02 & 10.31 & 10.11 \\
\hline
\end{tabular}

\subsection{Characterization of the Obtained Polymer}

3.5.1. The Solubility. The solubility of POPDA was investigated in N-methyl pyrrolidone, dimethylformamide (DMF), acetone, methanol, iso propanol, benzene, hexane, and chloroform. The solubility values are listed in Table 1 . The complete solubility was found in N-methyl pyrrolidone, then in DMF $2.235 \mathrm{~g} / \mathrm{L}$ followed by acetone $1.67 \mathrm{~g} / \mathrm{L}$, then in methanol $1.074 \mathrm{~g} / \mathrm{L}$ then followed by iso propanol $0.879 \mathrm{~g} / \mathrm{L}$ at $20^{\circ} \mathrm{C}$ but not soluble in benzene, hexane, and chloroform.

3.5.2. The Elemental Analysis. The data obtained from elemental analysis using oxygen flask combustion and a dosimat E415 titrator shows that the found carbon content of (POPDA) is lower than the calculated value. This is due to the formation of chromium carbide during step of heating and measuring process while the found values of nitrogen and hydrogen are 20.91 and 4.37, respectively, which are in good agreement with the calculated one for the suggested structure present in Scheme 1. By measuring another sample of the (POPDA) which was prepared by using ammonium persulfate as oxidant, the found value of carbon is higher than sample which is prepared by using potassium dichromate as oxidant. For more information about the chemical composition of (POPDA), the XPS study was conducted as mentioned under point 3.5.2.

\subsubsection{X-Ray Photoelectron Spectroscopy (XPS) Characterization}

(1) XPS Survey Elemental Composition. X-ray photoelectron spectroscopy (XPS) is used to study the composition of materials, which detect elements starting from $\mathrm{Li}(Z=3)$ and higher elements. Hydrogen $(Z=1)$ and helium $(Z=$ 2) cannot be detected due to the low probability of electron emission. XPS survey begins from 0 to $1400(\mathrm{eV})$ as shown in Figure 10. The XPS survey scan spectrum of the prepared polymer shows the presence of $\mathrm{C}, \mathrm{N}, \mathrm{O}, \mathrm{Cl}$, and $\mathrm{Cr}$. The $\mathrm{Cl}$ was present as doping anion in the prepared polymer. Chrome was found due to the polymer prepared using potassium dichromate as oxidant. It is possible for chromium ion $\left(\mathrm{Cr}^{+3}\right)$ to present between polymer chains as a sandwich-bonded $\mathrm{C}_{6} \mathrm{H}_{6}-\mathrm{C}_{6} \mathrm{H}_{6}$ groups as shown in Scheme 1 and the usual formation procedure is hydrolyzing the reaction mixture with dilute acid which gives the cation $\left(\mathrm{C}_{6} \mathrm{H}_{6}\right)_{2} \mathrm{Cr}^{3+}[30,31]$.

The XPS elemental analysis of the prepared polymer is given in Table 2. The data shows that there is a good agreement with the calculated one for the suggested structures present in Scheme 1.
(2) XPS Spectra of Poly(OPDA). Four main peaks were obtained for C1s spectra of poly(OPDA) as shown in Figure 11(a). The sharp peak appearing at $283.98 \mathrm{eV}$ is attributed to $\mathrm{C}-\mathrm{H}\left(\mathrm{C}_{1}\right)$ bond, while the peak appearing at $284.18 \mathrm{eV}$ is attributed to $\mathrm{C}-\mathrm{C}\left(\mathrm{C}_{2}\right)$ bond. The peak appearing at $285.08 \mathrm{eV}$ is assigned to $\mathrm{C}-\mathrm{N}\left(\mathrm{C}_{3}\right)$ bond while the peak appearing at $287.58 \mathrm{eV}$ is attributed to $\mathrm{C}-\mathrm{O}$ or $\mathrm{C}-\mathrm{N}^{+}\left(\mathrm{C}_{4}\right)$ bond [32-34].

N1s Figure 11(b) shows the XPS N1s spectrum of poly(OPDA) which has three distinct curves. The first two peaks are assigned to imine $(-\mathrm{N}=)$ at $398.58 \mathrm{eV}$ and amine $(-\mathrm{NH}-)$ at $399.23 \mathrm{eV}$. Moreover, the peak that appears at $400.58 \mathrm{eV}$ is due to positively charged nitrogen atom $\left(\mathrm{N}^{+}\right)$.

Two distinct oxygen species contribute to the oxygen $1 \mathrm{~s}$ signals in the conducting polymers (Figure 11(c)). The distinct energy peaks at 530.68 and $533.12 \mathrm{eV}$ could be attributed to $\mathrm{Cr}_{2} \mathrm{O}_{3}$ and $\mathrm{C}-\mathrm{OH}$, respectively.

The $\mathrm{Cl} 2 \mathrm{p}$ spectrum of poly(OPDA) is shown in Figure 11(d). In order to estimate the anion $\mathrm{Cl}$ at the surface, $\mathrm{Cl} 2 \mathrm{p}$ peaks are fitted with a number of spin-orbit doublets $\left(\mathrm{Cl} 2 \mathrm{p}_{1 / 2}\right.$ and $\left.\mathrm{Cl} 2 \mathrm{p}_{3 / 2}\right)$ with the B.E. for the $\mathrm{C12} \mathrm{p}_{3 / 2}$ peaks at about 197.36, 198.34, and $200.1 \mathrm{eV}$. The lowest and the highest B.E. components are attributable to the ionic and covalent chlorine species $\left(\mathrm{Cl}^{-}\right.$and $\left.-\mathrm{Cl}\right)$, respectively. The chlorine species $\left(\mathrm{Cl}^{*}\right)$ with the intermediate appear at B.E. of $198.34 \mathrm{eV}$. The lower B.E. value of the $\mathrm{Cl}^{*}$ species compared to the $\mathrm{Cl}$ species suggests the presence of chloride anion in a more positive environment, probably arising from an increase in the number of positively charged nitrogen in the polymer chain associated with the formation of polarons and bipolarons.

The Cr spectrum of (POPDA) is shown in Figure 11(e). The main components corresponding to different chemical chromium species were observed in the high-resolution $\mathrm{Cr}_{2} \mathrm{p}_{3 / 2}$ spectrums. The first peak at $576.18 \mathrm{eV} \pm 0.2 \mathrm{eV}$ was assigned to $\mathrm{Cr}_{2} \mathrm{O}_{3}$ which is in agreement with what was found by Chowdhury and Saha [13] and Stefanov et al. [35], also indicated by a distinct O1s peak at $530.68 \mathrm{eV}$ typical for $\mathrm{Cr}_{2} \mathrm{O}_{3}$ which may be adsorbed on polymer surface during chromous acid $\mathrm{H}_{2} \mathrm{Cr}_{2} \mathrm{O}_{3}$ oxidation process. There is also a component visible that corresponds to $\mathrm{Cr}_{2} \mathrm{p}_{1 / 2}$ at $586.08 \mathrm{eV}$, which was attributed to $\mathrm{Cr}^{3+}$. This data reveal that chromium ion is present between benzene rings of polymeric chain as shown in Scheme 1.

3.5.4. The Infrared Spectroscopic Analysis of (OPDA) Monomer and Its Analogs Polymer. The IR spectra of the OPDA and its polymer (POPDA) are represented in Figure 12, while the absorption band values and their assignments are summarized in Table 3 . The medium absorption band appearing at 


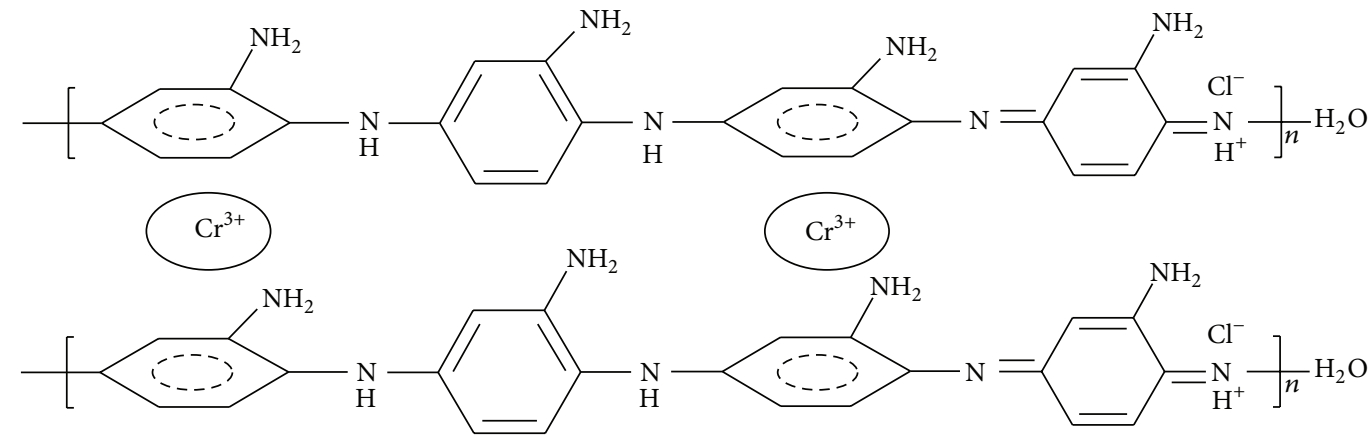

Scheme 1: Structure of the prepared (POPDA).

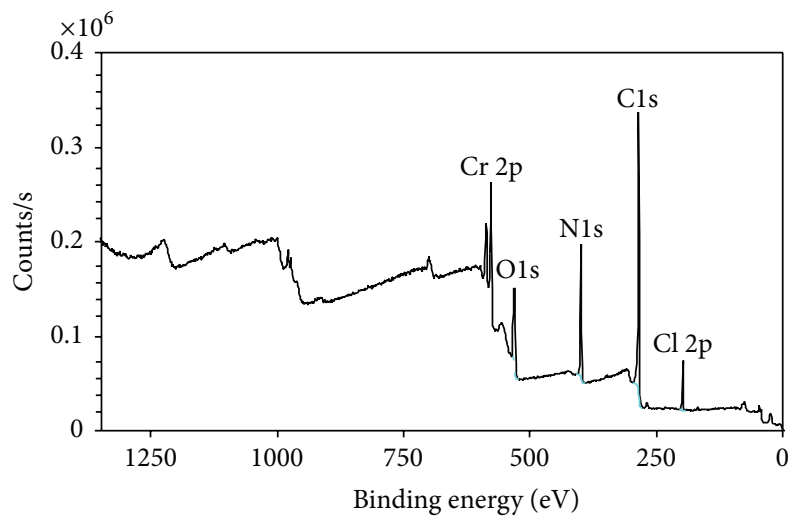

FIGURE 10: X-ray photoelectron spectroscopy (XPS) survey elemental composition of poly-o-phenylenediamine (POPDA).

$453 \mathrm{~cm}^{-1}$, which could be attributed to bending deformation of $\mathrm{N}-\mathrm{H}$ group attached to benzene ring in case of monomer, appears at $518 \mathrm{~cm}^{-1}$ with slight shift in case of polymer. The broad absorption band appearing at $778 \mathrm{~cm}^{-1}$ in case of monomer, which could be attributed to out of plane deformation of $\mathrm{CH}$ for 1,2-disubstituted benzene, appears at $748 \mathrm{~cm}^{-1}$ with slight shift in case of polymer. A series of absorption bands appear in the region from 924 to $1152 \mathrm{~cm}^{-1}$ which could be attributed to the out of plane $\mathrm{C}-\mathrm{H}$ deformation of 1,2-disubistuition benzene ring in case of monomer and $1,2,4$ tri-substituted of benzene ring, in case of polymer. The sharp absorption bands appear at $1336 \mathrm{~cm}^{-1}$ in case of the monomer, which could be attributed to symmetric stretching vibration of $\mathrm{C}-\mathrm{N}$, appears at $1362 \mathrm{~cm}^{-1}$ with slight shift in case of polymer. The sharp absorption band appearing at $1490 \mathrm{~cm}^{-1}$ in case of the monomer may be attributed to $\mathrm{C}=\mathrm{C}$ aromatic stretching vibration, which appears at $1500 \mathrm{~cm}^{-1}$ with slight shift in case of polymer. The sharp absorption band appearing at $1630 \mathrm{~cm}^{-1}$ in case of the monomer, which may be attributed to $\mathrm{C}=\mathrm{C}$ deformation of benzene ring, appears at $1621 \mathrm{~cm}^{-1}$ with slight shift in case of polymer. The shoulder absorption band appears at $3032 \mathrm{~cm}^{-1}$ in case of the monomer which could be attributed to symmetric stretching vibration of $\mathrm{C}-\mathrm{H}$ in aromatic ring and disappears in case of polymer. The triplet absorption bands appearing at 3190, 3281, and $3370 \mathrm{~cm}^{-1}$ in case of monomer could be attributed to asymmetric stretching vibration for $\mathrm{NH}$ group, but in case of
TABLE 3: Infrared absorption bands and their assignments of ophenylene-diamine monomer (OPDA) and its analogs polymer (POPDA).

\begin{tabular}{|c|c|c|}
\hline \multicolumn{2}{|c|}{ Wave number $\left(\mathrm{cm}^{-1}\right)$} & \multirow{2}{*}{ Assignments } \\
\hline $\begin{array}{l}\text { (OPDA) } \\
\text { Monomer }\end{array}$ & $\begin{array}{l}\text { (POPDA) } \\
\text { Polymer }\end{array}$ & \\
\hline $453^{\mathrm{m}}$ & - & \multirow{2}{*}{$\begin{array}{l}\text { Bending deformation of } \mathrm{NH} \text { in primary } \\
\text { aromatic amines }\end{array}$} \\
\hline- & $518^{\mathrm{m}}$ & \\
\hline $748^{\mathrm{b}}$ & - & \multirow{2}{*}{$\begin{array}{l}\text { Out-of-plane bending deformation of } \\
\mathrm{CH} \text { in } 1,2 \text { disubstituted in benzene ring }\end{array}$} \\
\hline- & $761^{\mathrm{b}}$ & \\
\hline $810^{\mathrm{s}}$ & - & \multirow{2}{*}{$\begin{array}{l}\text { Out-of-plane deformation showing } \\
\text { 1,4-disubistuition in the benzene ring }\end{array}$} \\
\hline- & $833^{\text {sh }}$ & \\
\hline $924^{\mathrm{s}}$ & - & \multirow{6}{*}{$\begin{array}{l}\text { Plane } \mathrm{C}-\mathrm{H} \text { deformation of } \\
\text { 1,2-disubistuition of benzene ring }\end{array}$} \\
\hline- & $1044^{\mathrm{w}}$ & \\
\hline $1056^{\mathrm{m}}$ & - & \\
\hline $1117^{\mathrm{s}}$ & - & \\
\hline- & $1133^{\mathrm{w}}$ & \\
\hline 1152 & - & \\
\hline $1336^{\mathrm{s}}$ & $1362^{\text {sh }}$ & $\begin{array}{l}\text { Symmetric stretching vibration for } \mathrm{C}-\mathrm{O} \\
\text { or } \mathrm{C}-\mathrm{N} \text { group }\end{array}$ \\
\hline $1490^{\mathrm{s}}$ & $1500^{\mathrm{b}}$ & $\begin{array}{l}\text { Symmetric stretching vibration for } \mathrm{C}-\mathrm{C} \\
\text { aromatic }\end{array}$ \\
\hline $1590^{s}$ & - & $\begin{array}{l}\text { Stretching vibration of } \mathrm{C}-\mathrm{N} \text { or } \\
\text { combination band for protonated } \\
\text { primary aromatic amine }\end{array}$ \\
\hline $1630^{\mathrm{s}}$ & $1621^{\mathrm{b}}$ & $\mathrm{N}-\mathrm{H}$ deformation of secondary amine \\
\hline $3032^{\text {sh }}$ & - & Symmetric stretching vibration of $\mathrm{N}-\mathrm{H}$ \\
\hline $3281^{\mathrm{s}}$ & $3354^{\mathrm{m}}$ & Asymmetric stretching vibration for $\mathrm{NH}$ \\
\hline $2930^{\mathrm{sh}}$ & $3354^{\mathrm{b}}$ & $\begin{array}{l}\text { Asymmetric stretching vibration for } \mathrm{CH} \\
\text { group in aliphatic chain }\end{array}$ \\
\hline $3370^{\mathrm{s}}$ & - & Symmetric stretching vibration of $=\mathrm{C}-\mathrm{H}$ \\
\hline
\end{tabular}

s: sharp; m: medium; w: weak; b: broad; sh: shoulder.

polymer a broad absorption band that appears at $3354 \mathrm{~cm}^{-1}$ could be attributed to asymmetric stretching vibration for $\mathrm{NH}$ group and $\mathrm{OH}$ group present in the polymer structure.

3.5.5. The UV-Visible Spectroscopic Study of OPDA Monomer and Its Analogs Polymer. The UV-visible spectra of OPDA 


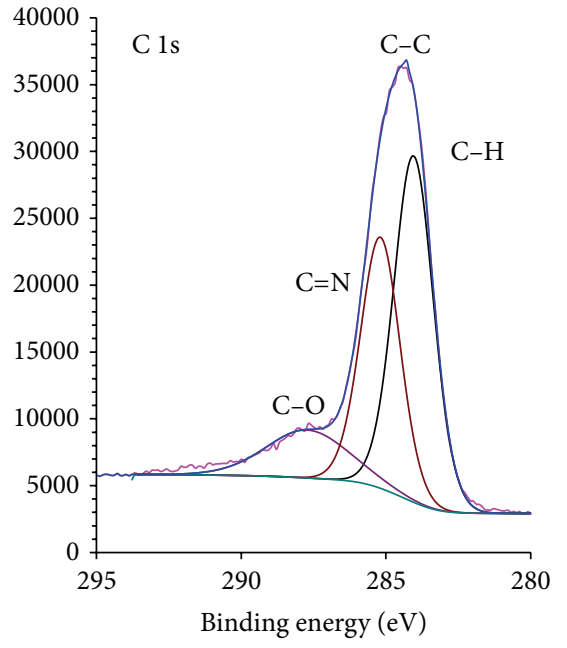

(a)

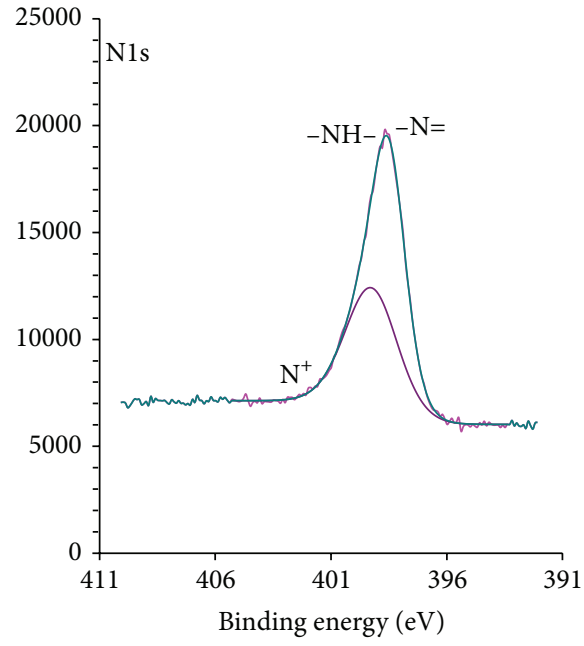

(b)

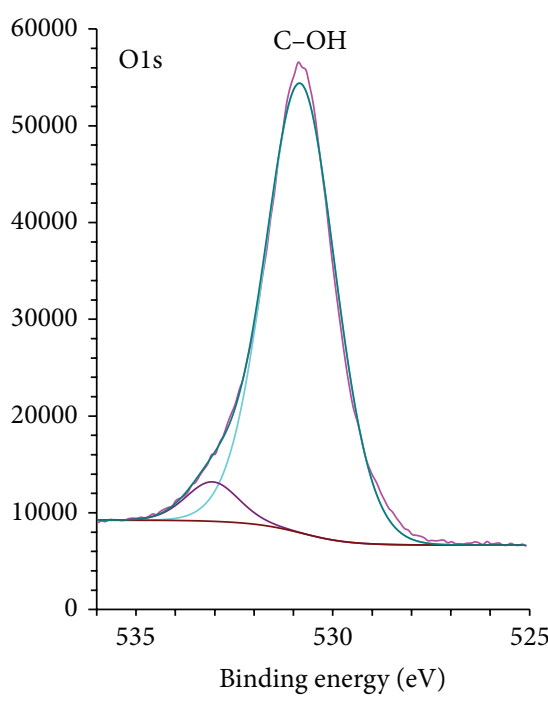

(c)

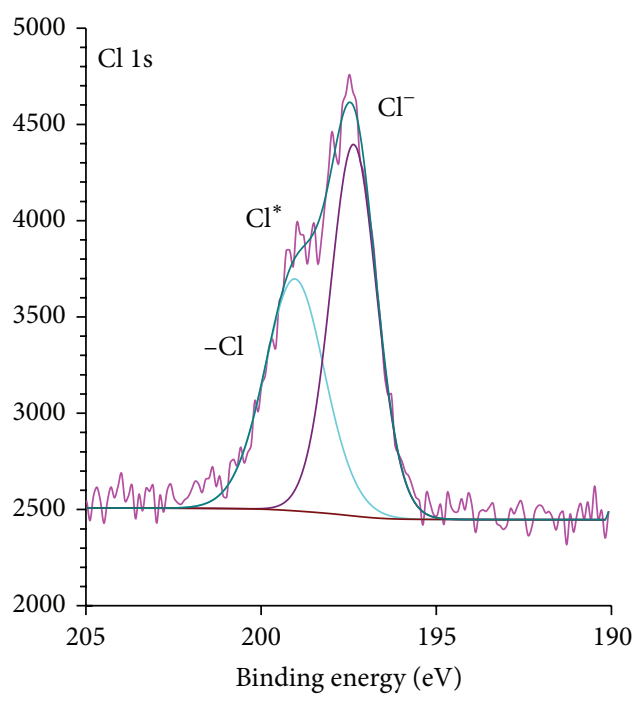

(d)

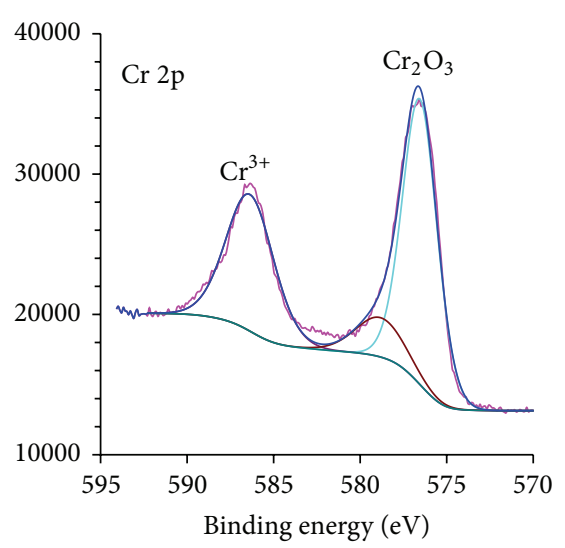

(e)

FIGURE 11: X-ray photoelectron spectroscopy (XPS) spectra of (POPDA).

and its polymer are represented in Figure 13; the spectra show the following absorption bands:

(1) in case of monomer, two absorption bands appear at $\lambda_{\max }=219$ and $240 \mathrm{~nm}$ which may be attributed to $\pi$ $\pi^{*}$ transition ( $\mathrm{E}_{2}$-band) of the benzene ring and the $\beta$-band $\left(A_{1 \mathrm{~g}}-B_{2 \mathrm{u}}\right)$;

(2) in case of polymer, two absorption bands appear at $\lambda_{\max }=221$ and $243 \mathrm{~nm}$ which may be attributed to $\pi-\pi^{*}$ transition showing a bathochromic shift. Beside these two bands, broad absorption band appears in the visible region at $\lambda_{\max }=417 \mathrm{~nm}$ which may be due to the high conjugation of the aromatic polymeric chain.

3.5.6. Thermal Gravimetric Analysis (TGA) of Poly O-Phenylenediamine. Thermogravimetric analysis (TGA) for the prepared polymer has been investigated and the TGA-curve is represented in Figure 14. The calculated and found data for the prepared polymers are summarized in Table 4. The thermal degradation steps are summarized as follows:

(1) the first stage includes the loss of one water molecule in the temperature range between 29.5 and $122.6^{\circ} \mathrm{C}$; the weight loss of this step was found to be $3.21 \%$ which is in a good agreement with the calculated one;

(2) in the second stage, in the temperature range between 122.6 and $203.8^{\circ} \mathrm{C}$, the weight loss was found to be $6.65 \%$, which could be attributed to the loss of one $\mathrm{HCl}$ molecule. The calculated weight loss is in good agreement with the found one;

(3) in the third stage, in the temperature range between 203.8 and $320.3^{\circ} \mathrm{C}$, the weight loss was found to be $11.79 \%$, which is attributed to the loss of four $\left(\mathrm{NH}_{2}\right)$ 


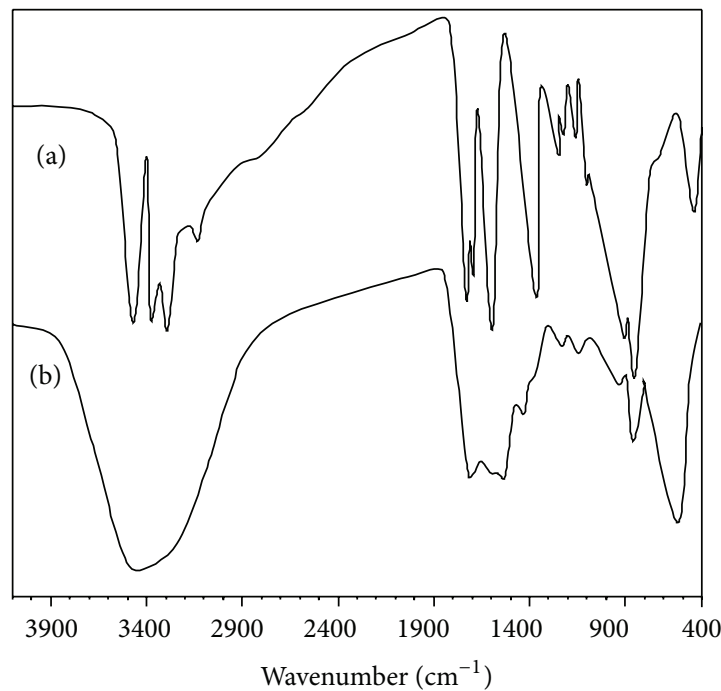

FIGURE 12: The infrared spectrum of o-phenylenediamine (OPDA) (a) and it analogous polymer (POPDA) (b).

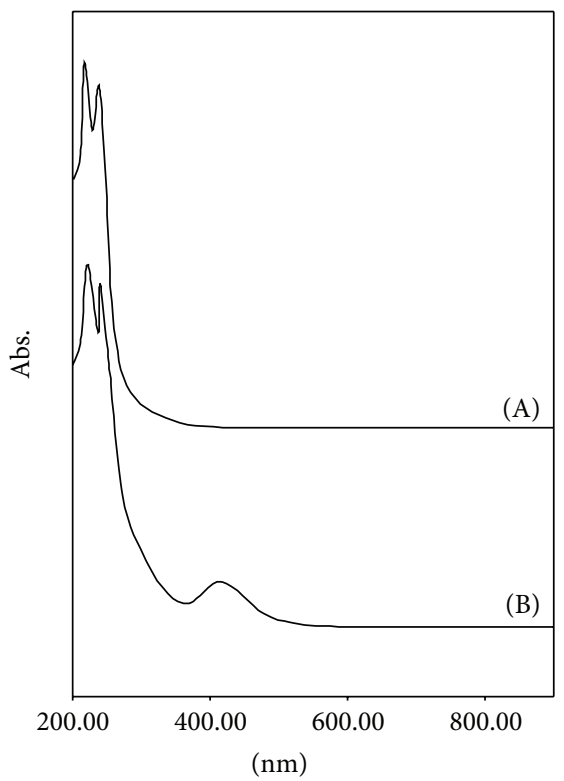

FIGURE 13: UV-visible spectra of o-phenylenediamine (OPDA) (A) and it analogous polymer (POPDA) (B).

groups. The calculated weight loss for this stage is equal to $12.11 \%$;

(4) in the fourth stage, in the temperature range between 320.3 and $400.0^{\circ} \mathrm{C}$, the weight loss was found to be $16.95 \%$, which could be attributed to the loss of one molecule of $\mathrm{C}_{6} \mathrm{H}_{3}-\mathrm{NH}$. The calculated weight loss of this stage is equal to $17.22 \%$;

(5) in the fifth stage, in the temperature range between 400.0 and $523.4^{\circ} \mathrm{C}$, the weight loss was found to be $13.78 \%$, which is attributed to the loss of one molecule of phenyl ring. The calculated weight loss of this stage is equal to $14.19 \%$;
(6) in the last stage, above $523.38^{\circ} \mathrm{C}$, the remaining polymer molecule was found to be $47.62 \%$ including the metallic residue, but the calculated one was found to be $46.46 \%$.

3.5.7. The X-Ray Diffraction Analysis and Transmission Electron Microscope. The X-Ray diffraction patterns of the prepared polymer are represented in Figure 15. The figure shows that the prepared poly o-phenylenediamine is completely amorphous.

Morphology of poly o-phenylenediamine was characterized by transmission electron microscope. Figure 16 shows 


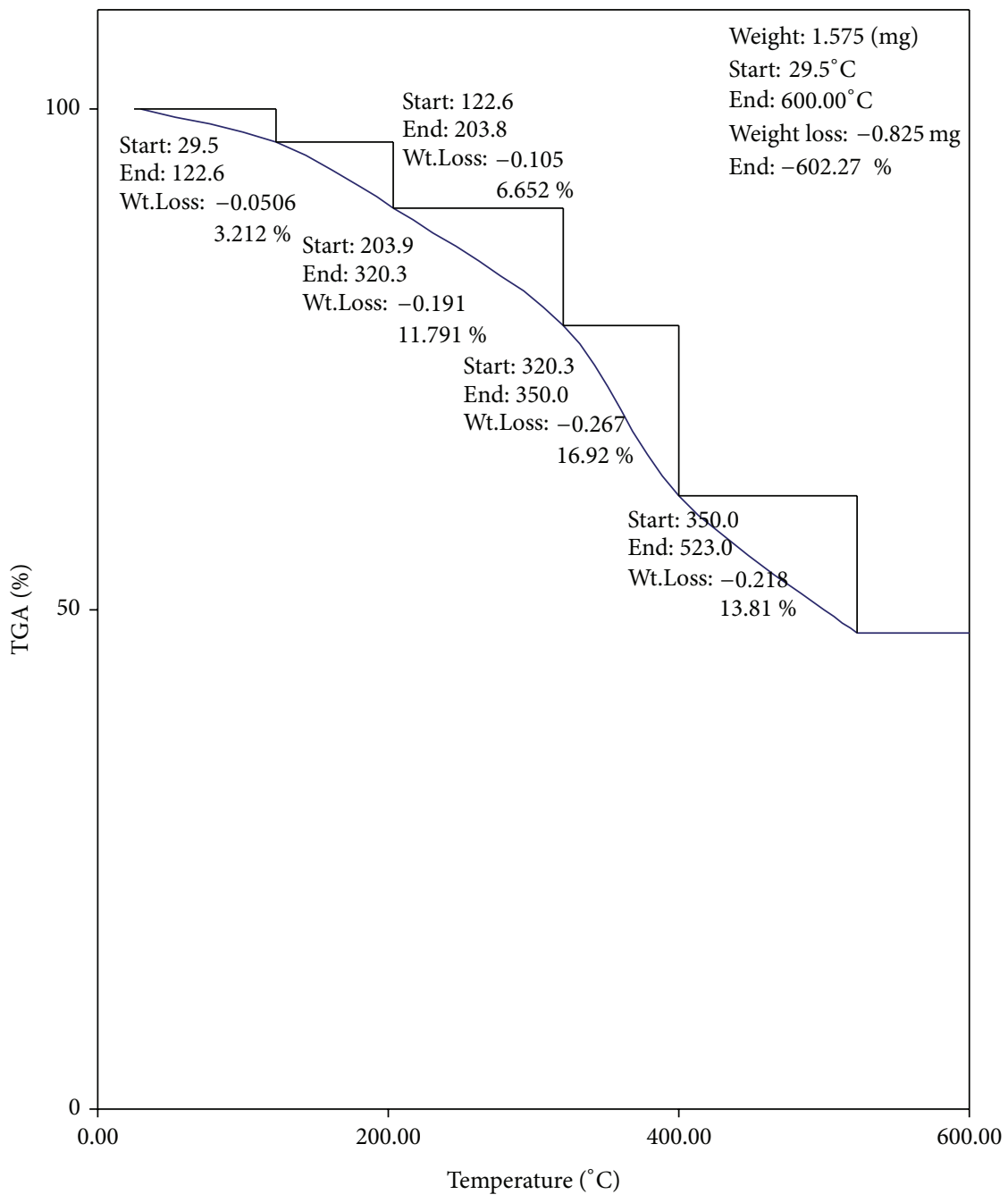

FIGURE 14: The thermal gravimetric analysis (TGA) for (POPDA).

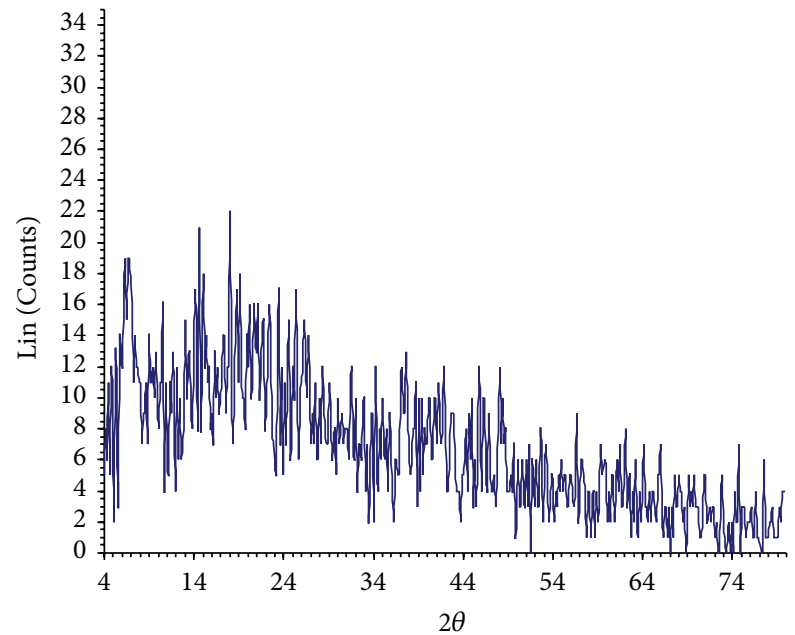

FIGURE 15: X-ray poly-o-phenylenediamine (POPDA). 


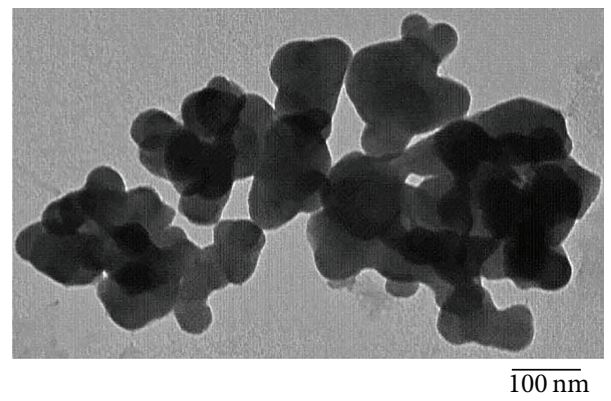

FIGURE 16: The transmission electron microscope of POPDA.

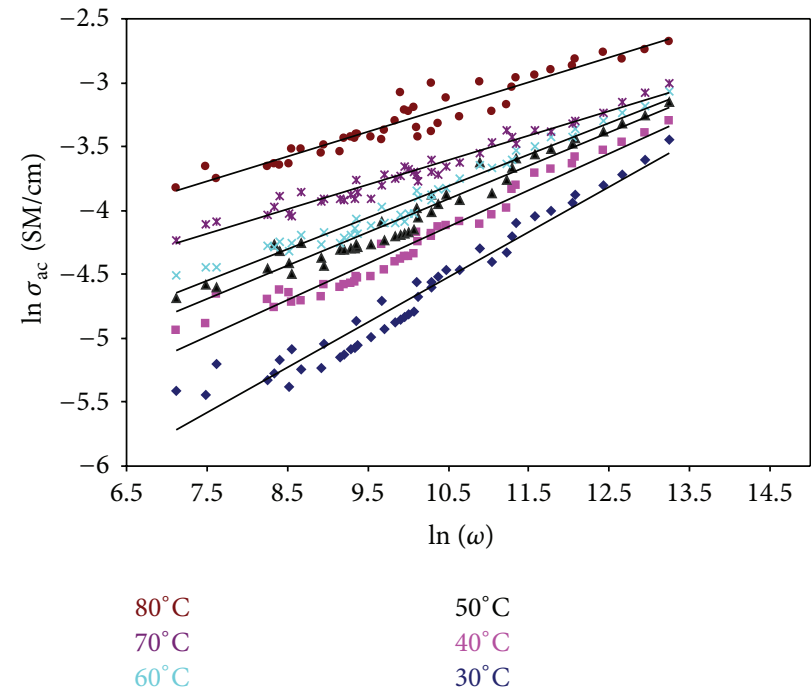

FIGURE 17: ac conductivity versus angular frequency for poly-o-phenylenediamine (POPDA) with frequency at different temperatures.

TABLE 4: Thermogravimetric data of poly-o-phenylenediamine (POPDA).

\begin{tabular}{|c|c|c|c|c|}
\hline \multirow{2}{*}{ Name } & \multirow{2}{*}{$\begin{array}{l}\text { Temperature } \\
\text { range }{ }^{\circ} \mathrm{C}\end{array}$} & \multicolumn{2}{|c|}{ Weight loss (\%) } & \multirow{2}{*}{$\begin{array}{l}\text { The removed } \\
\text { molecule }\end{array}$} \\
\hline & & Calc. & Found & \\
\hline \multirow{6}{*}{ Poly(POPDA) } & $29.5-122.6$ & 3.41 & 3.212 & $\mathrm{H}_{2} \mathrm{O}$ \\
\hline & $122.6-203.8$ & 6.91 & 6.652 & $\mathrm{HCl}$ \\
\hline & $203.8-320.3$ & 12.11 & 11.791 & $4 \mathrm{NH}_{2}$ \\
\hline & $320.3-400.00$ & 17.22 & 16.952 & $\mathrm{C}_{6} \mathrm{H}_{3}-\mathrm{NH}$ \\
\hline & $400-523.40$ & 14.19 & 13.778 & $\mathrm{C}_{6} \mathrm{H}_{3}$ \\
\hline & $\begin{array}{l}\text { Remaining } \\
\text { weight (\%) } \\
\text { above } 600\end{array}$ & 46.17 & 47.62 & - \\
\hline
\end{tabular}

TEM image of poly o-phenylenediamine which nearly spherical or ellipsoidal particles with approximate diameter 60$120 \mathrm{~nm}$ either separated or linked with each other.

3.6. ac Conductivity $\left(\sigma_{\mathrm{ac}}\right)$. Figure 17 represent the variation in ac conductivity $\left(\sigma_{\mathrm{ac}}\right)$ for (POPDA) as a function of frequency and temperature. It is observed that the value of ac conductivity increases with the increase of frequency. This behavior is in good agreement with the random free energy model proposed by Dyre [36]. According to this model, conductance increases as a function of frequency in many solids, including polymers, which can be explained on the basis of any hopping model. The rise in conductivity upon increasing the frequency and temperature is common for disordered conducting polymer. As can be seen, each curve displays a conductivity dispersion, which is strongly dependent on frequency and shows weaker temperature dependant.

The recorded conductivity value at room temperature of POPDA was found $0.0352 \mathrm{~S} / \mathrm{cm}$ which is higher than conductivity of polyaniline-polyvinyl alcohol blends $10.5 \times$ $10^{-5} \mathrm{~S} \mathrm{~cm}^{-1}$ [37] and ac conductivity of $\mathrm{HCl}$ doped polyaniline synthesized by the interfacial polymerization technique $6.2 \times 10^{-5} \mathrm{~S} \mathrm{~cm}^{-1}$ [38]. Also, the ac conductivity of POPDA is higher than polyaniline loaded with $10 \%$ molybdenum trioxide composites $0.025 \mathrm{~s} / \mathrm{cm}$ [39] but lower than the determined value of ac conductivity polyaniline prepared by $\mathrm{K}_{2} \mathrm{Cr}_{2} \mathrm{O}_{7}$ as oxidant $1.922 \mathrm{~S} \mathrm{~cm}^{-1}$. Such difference could be attributed to the different disorder of each composite, substituted function group, and different used dopant. 


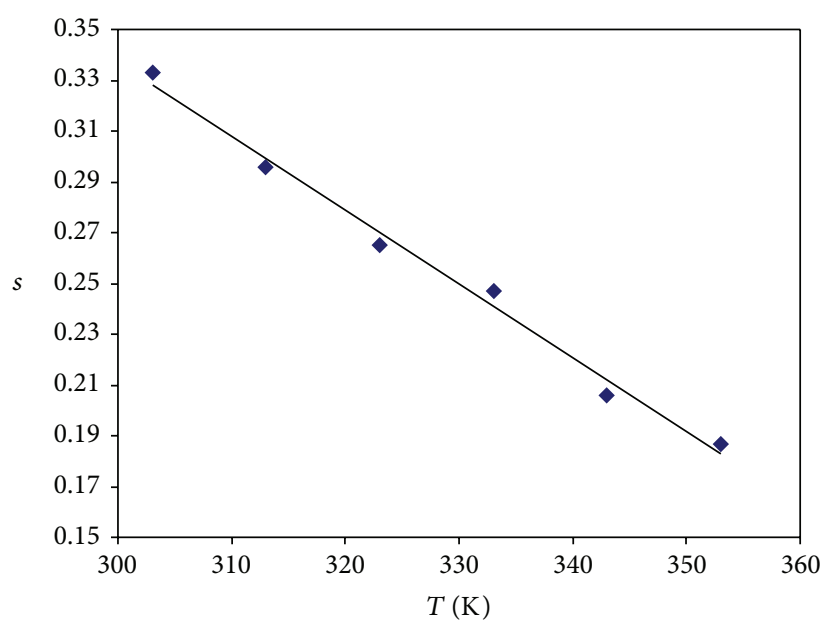

FIGURE 18: Frequency exponent $(s)$ versus temperature for poly-o-phenylenediamine (POPDA).

In general, for amorphous conducting material, disordered systems, low mobility polymers, and even crystalline materials, the ac conductivity $\left(\sigma_{\mathrm{ac}}\right)$ as a function of frequency can obey a power law with frequency [40]. The ac conductivity $\left(\sigma_{\mathrm{ac}}\right)$ over a wide range of frequencies can be expressed as

$$
\sigma_{\mathrm{ac}}(\omega)=A \omega^{s}
$$

where $A$ is a complex constant and the index $(s)$ is frequency exponent and $\omega$ is the angular frequency $(\omega=2 \pi f)$.

Figure 17 shows the relation between $\operatorname{Ln} \sigma_{\mathrm{ac}}$ and $\operatorname{Ln} \omega$ at different temperatures. The value of $(s)$ at each temperature has been calculated from the slope of $\ln \sigma(\omega)$ versus $\ln (\omega)$ plot. As shown in Figure 18 the calculated values of $(s)$ for (POPDA) sample are less than unity. The microscopic conduction mechanisms of disordered systems are governed by two physical processes such as classical hopping or quantum mechanical tunneling of charge carries over the potential barrier separating two energetically favorable centers in a random distribution. The exact nature of charge transport is mainly obtained experimentally from the temperature variation of exponent (s) [41]. The temperature exponent(s) dependences for (POPDA) sample reveal that the frequency exponent(s) decreases with the increase of temperature. This behavior is only observed in the correlated barrier hopping model proposed by Elliott [42].

\section{Conclusions}

In the present work POPDA polymer incorporated with potassium dichromate and $\mathrm{HCl}$ has been successfully achieved. The optimum yield formation of POPDA is obtained at $0.3 \mathrm{M}$ potassium dichromate $0.1 \mathrm{M}$ of the monomer and $0.2 \mathrm{M}$ hydrochloric acid concentrations. The initial and overall rate of polymerization reaction increases with increasing the oxidant, monomer, and $\mathrm{HCl}$ concentrations. The exponent of oxidant, monomer, and $\mathrm{HCl}$ was found to be $1.011,1.045$, and 0.954 , respectively. The chrome is present between polymer chains as sandwich-bonded $\mathrm{C}_{6} \mathrm{H}_{6}-$ $\mathrm{C}_{6} \mathrm{H}_{6}$ groups and the usual formation procedure hydrolyzes the reaction mixture with dilute acid which gives the cation $\left(\mathrm{C}_{6} \mathrm{H}_{6}\right)_{2} \mathrm{Cr}^{3+}$. The ac conductivity increases with the increase of frequency and temperature. The microscopic conduction mechanism of charge which carries over the potential barrier in polymer backbone is classical hopping model.

\section{Conflict of Interests}

The authors declare that there is no conflict of interests regarding the publication of this paper.

\section{References}

[1] P. C. Wang, L. H. Liu, D. A. Mengistie et al., "Transparent electrodes based on conducting polymers for display applications," Displays, vol. 34, no. 4, pp. 301-314, 2013.

[2] M. Jaymand, "Recent progress in chemical modification of polyaniline," Progress in Polymer Science, vol. 38, no. 9, pp. 12871306, 2013.

[3] Q. Ju, Y. Shi, and Kan, "Performance study of magnesium-polyaniline rechargeable battery in 1-ethyl-3-methylimidazolium ethyl sulfate electrolyte," Synthetic Metals, vol. 178, pp. 27-33, 2013.

[4] C. Steffens, A. Manzoli, J. E. Oliveira, F. L. Leite, D. S. Correa, and P. S. P. Herrmann, "Bio-inspired sensor for insect pheromone analysis based on polyaniline functionalized AFM cantilever sensor," Sensors and Actuators B: Chemical, vol. 191, pp. 643-649, 2014.

[5] L. Wang, E. Hua, M. Liang et al., "Graphene sheets, polyaniline and AuNPs based DNA sensor for electrochemical determination of BCR/ABL fusion gene with functional hairpin probe," Biosensors and Bioelectronics, vol. 51, pp. 201-207, 2014.

[6] V. Talwar, O. Singh, and R. Singh, " $\mathrm{ZnO}$ assisted polyaniline nanofibers and its application as ammonia gas sensor," Sensors and Actuators B, vol. 191, pp. 276-282, 2014.

[7] Y. Moon, J. yun, and H. Kim, "Synergetic improvement in electromagnetic interference shielding characteristics of polyaniline-coated graphite oxide/gamma- $\mathrm{Fe}_{2} \mathrm{O}_{3} / \mathrm{BaTiO}_{3}$ 
nanocomposites," Journal of Industrial and Engineering Chemistry, vol. 19, no. 2, pp. 493-497, 2013.

[8] G. Gupta, N. Birbilis, A. B. Cook, and A. S. Khanna, "Polyaniline-lignosulfonate/epoxy coating for corrosion protection of AA2024-T3," Corrosion Science, vol. 67, pp. 256-267, 2013.

[9] R. Karthikaiselvi and S. Subhashini, "Study of adsorption properties and inhibition of mild steel corrosion in hydrochloric acid media by water soluble composite poly (vinyl alcohol-omethoxy aniline)," Journal of the Association of Arab Universities for Basic and Applied Sciences, 2013.

[10] X. Martin and K. Mullen, "Designing p-conjugated polymers for organic electronics," Progress in Polymer Science, vol. 38, no. 12, pp. 1832-1908, 2013.

[11] K. Gopodinova and L. Terlemezyan, "Conducting polymers prepared by oxidative polymerization: polyaniline," Progress in Polymer Science, vol. 23, no. 8, pp. 1443-1484, 1998.

[12] K. Gurunathan, A. V. Murugan, R. Marimuthu, U. P. Mulik, and D. P. Amalnerkar, "Electrochemically synthesised conducting polymeric materials for applications towards technology in electronics, optoelectronics and energy storage devices," Materials Chemistry and Physics, vol. 61, no. 3, pp. 173-191, 1999.

[13] P. Chowdhury and B. Saha, "Potassium dichromate initiated polymerization of aniline," Indian Journal of Chemical Technology, vol. 12, pp. 671-675, 2005.

[14] R. Hirase, T. Shikata, and M. Shirai, "Selective formation of polyaniline on wool by chemical polymerization, using potassium iodate," Synthetic Metals, vol. 146, no. 1, pp. 73-77, 2004.

[15] K. Gopalakrishnan, M. Elango, and M. Thamilsevan, "Optical studies on nano-structured conducting Polyaniline prepared by chemical oxidation method," Archives of Physics Research, vol. 3, no. 4, pp. 315-319, 2012.

[16] K. Molapo, P. M. Ndangili, R. F. Ajayi et al., "Electronics of conjugated polymers (I): polyaniline," International Journal of Electrochemical Science, vol. 7, pp. 11859-11875, 2012.

[17] Y. Cao, P. Smith, and A. Heeger, "Counter-ion induced processibility of conducting polyaniline and of conducting polyblends of polyaniline in bulk polymers," Synthetic Metals, vol. 48, no. 1, pp. 91-97, 1992.

[18] Y. Kang, M. Lee, and S. Rhee, "Polyaniline with surfactant counterions: conducting polymer materials which are processible in the conducting form," Synthetic Metals, vol. 57, no. 1, pp. 34713482, 1993.

[19] Y. Kang, M. Lee, and S. Rhee, "Electrochemical properties of polyaniline doped with poly(styrenesulfonic acid)," Synthetic Metals, vol. 52, no. 3, pp. 319-328, 1992.

[20] A. Pron, J. Laska, J. E. Osterholm, and P. Smith, "Processable conducting polymers obtained via protonation of polyaniline with phosphoric acid esters," Polymer, vol. 34, no. 20, pp. 42354240, 1993.

[21] S. M. Sayyah, H. M. Abd El-Salam, and E. M. S. Azzam, "Surface activity of monomeric and polymeric (3-alkyloxy aniline) surfactants," International Journal of Polymeric Materials, vol. 54, no. 6, pp. 541-555, 2005.

[22] S. M. Sayyah, A. A. Bahgat, and H. M. Abd El-Salam, "Kinetic studies of the aqueous oxidative polymerization of 3hydroxyaniline and characterization of the polymer obtained," International Journal of Polymeric Materials, vol. 51, no. 3, pp. 291-314, 2002.
[23] S. M. Sayyah, A. A. Abd El-Khalek, A. A. Bahgat, and H. A. Abd El-Salam, "Kinetic studies of the chemical polymerization of substituted aniline in aqueous solutions and characterization of the polymer obtained Part 1. 3-Chloroaniline," Polymer International, vol. 50, no. 2, pp. 197-206, 2001.

[24] S. M. Sayyah and H. M. Abd El-Salam, "Aqueous oxidative polymerization of $\mathrm{N}$-methyle aniline in acid medium and characterization of the obtained polymer," International Journal of Polymeric Materials, vol. 52, pp. 1087-1111, 2003.

[25] S. M. Sayyah, A. A. Abd El-Khalek, A. A. Bahgat, and H. M. Abd El-Salam, "Kinetic studies of the polymerization of substituted aniline in aqueous solutions and characterization of the polymer obtained. Part 2.3-methylaniline," International Journal of Polymeric Materials, vol. 49, no. 1, pp. 25-49, 2001.

[26] S. M. Sayyah, H. M. Abd El-Salam, and A. A. Bahgat, "Aqueous oxidative polymerization of 3-methoxyaniline and characterization of its polymer,' International Journal of Polymeric Materials, vol. 51, no. 10, pp. 915-938, 2002.

[27] S. M. Sayyah, A. A. Bahgat, and H. M. Abd El-Salam, "Kinetic studies of the aqueous oxidative polymerization of 3hydroxyaniline and characterization of the polymer obtained," International Journal of Polymeric Materials, vol. 51, no. 3, pp. 291-314, 2002.

[28] S. M. Sayyah, A. A. Abd El-Khalek, A. A. Bahgat, and H. A. Abd El-Salam, "Kinetic studies of the chemical polymerization of substituted aniline in aqueous solutions and characterization of the polymer obtained Part 1. 3-Chloroaniline," Polymer International, vol. 50, no. 2, pp. 197-206, 2001.

[29] S. M. Sayyah and H. Abd El Salam, "Oxidative chemical polymerization of some 3-alkyloxyaniline surfactants and characterization of the obtained polymers," International Journal of Polymeric Materials and Polymeric Biomaterials, vol. 55, no. 12, pp. 1075-1093, 2006.

[30] F. Cotton and G. Wilkinson, Advanced Inorganic Chemistry, 3rd edition, 1972.

[31] H. Zeiss, P. Whealty, and H. Winkler, Benzoic Material Complexes, Ronald Press, 1966.

[32] A. Qaiser, M. Hyland, and D. Patterson, "Effects of various polymerization techniques on PANI deposition at the surface of cellulose ester microporous membranes: XPS and electrical conductivity studies," Synthetic Metals, vol. 162, no. 11-12, pp. 958-967, 2012.

[33] J. Li, X. Qian, L. Wang, and X. An, "XPS characterization and percolation behavior of polyaniline-coated conductive paper," BioResources, vol. 5, no. 2, pp. 712-726, 2010.

[34] K. Tan and B. Tan, "The chemical nature of the nitrogens in polypyrrole and polyaniline: a comparative study by X-ray photoelectron spectroscopy," Journal of Chemical Physics, vol. 94, no. 8, article 5382, 1991.

[35] P. Stefanov, D. Stoychev, M. Stoycheva, and T. Marinov, "XPS and SEM studies of chromium oxide films chemically formed on stainless steel 316 L," Materials Chemistry and Physics, vol. 65, no. 2, pp. 212-215, 2000.

[36] J. Dyre, "The random free-energy barrier model for ac conduction in disordered solids," Journal of Applied Physics, vol. 64, no. 5, article 2456, 1988.

[37] P. Dutta, S. Biswas, M. Ghosh, S. K. De, and S. Chatterjee, "The $\mathrm{dc}$ and ac conductivity of polyaniline-polyvinyl alcohol blends," Synthetic Metals, vol. 122, no. 2, pp. 455-461, 2001.

[38] P. Chutia and A. Kumar, "Electrical, optical and dielectric properties of $\mathrm{HCl}$ doped polyaniline nanorods," Physica B, vol. 436, pp. 200-207, 2014. 
[39] K. R. Anilkumar, A. Parveen, G. R. Badiger, and M. V. N. Ambika Prasad, "Effect of molybdenum trioxide $\left(\mathrm{MoO}_{3}\right)$ on the electrical conductivity of polyaniline," Physica B: Condensed Matter, vol. 404, no. 12-13, pp. 1664-1667, 2009.

[40] A. Paphanassiou, "The power law dependence of the a.c. conductivity on frequency in amorphous solids," Journal of Physics D: Applied Physics, vol. 35, no. 17, article L88, 2002.

[41] A. Dey, S. De, A. De, and S. K. De, "Characterization and dielectric properties of polyaniline- $\mathrm{TiO}_{2}$ nanocomposites," Nanotechnology, vol. 15, pp. 1277-1283, 2004.

[42] S. Elliott, "A.c. conduction in amorphous chalcogenide and pnictide semiconductors," Advances in Physics, vol. 36, no. 2, pp. 135-217. 

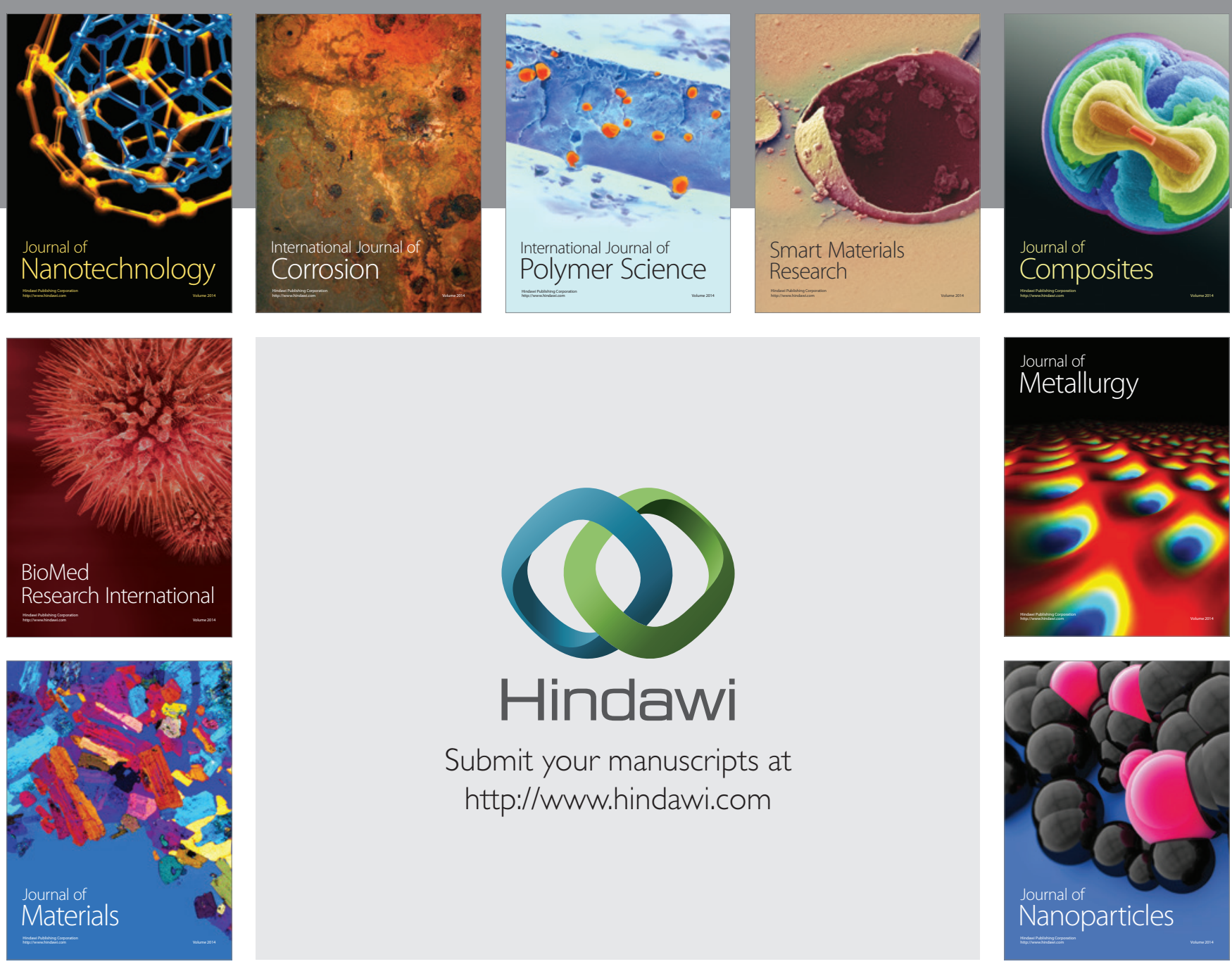

Submit your manuscripts at http://www.hindawi.com
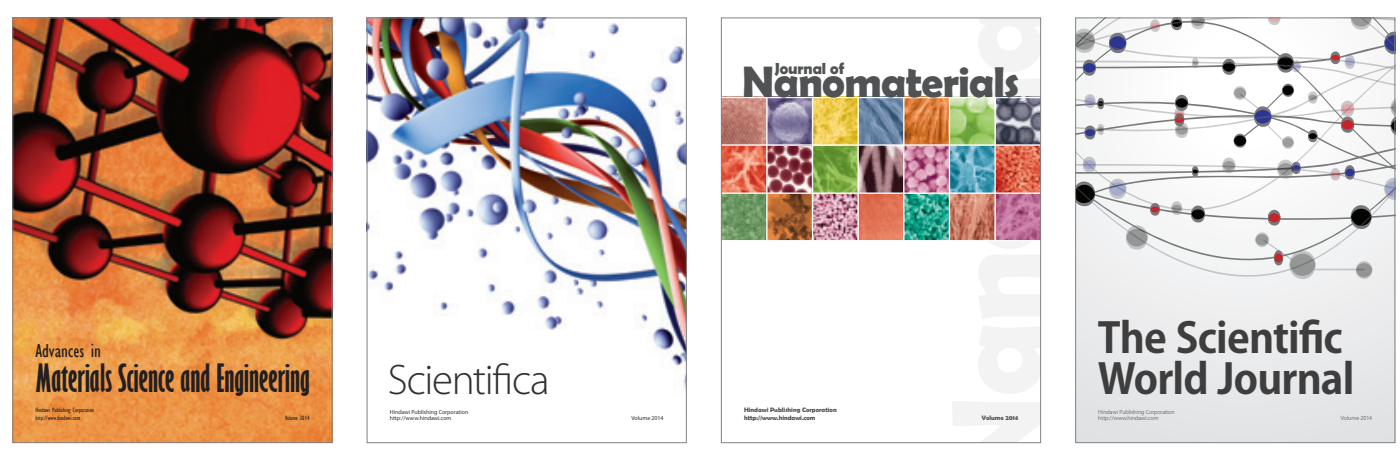

\section{The Scientific World Journal}
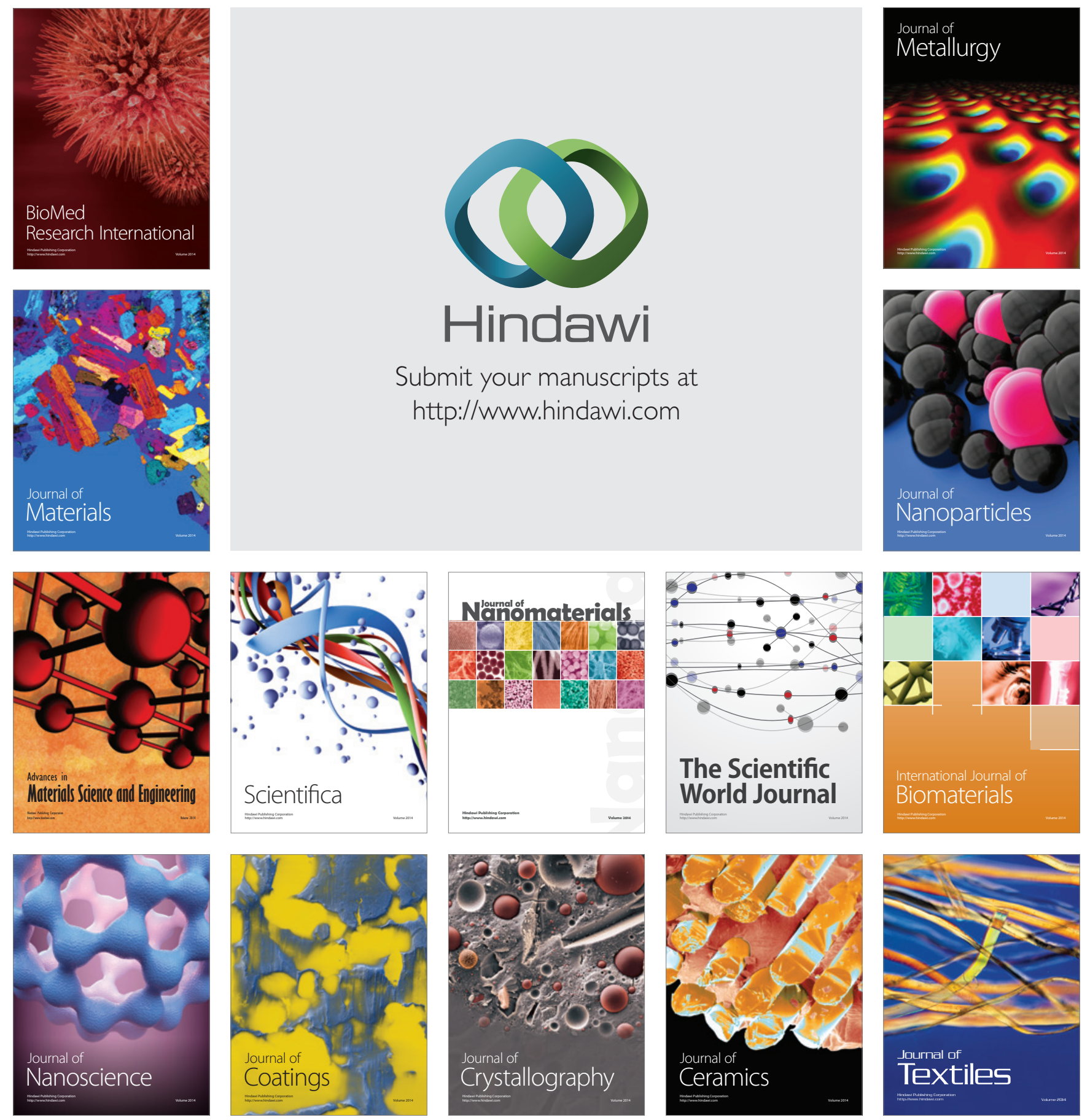